Check for updates

Cite this: RSC Adv., 2019, 9, 14302

\title{
Review of $\alpha$-nucleosides: from discovery, synthesis to properties and potential applications
}

\author{
Guangcheng Ni, † Yuqi Du, $\uparrow$ Fan Tang, Jiang Liu, ${ }^{*}$ Hang Zhao (D) * and Qianming Chen
}

\begin{abstract}
Nucleic acids play an important role in the genetic process of organisms; nucleosides, the building block of nucleic acids, typically exist in nature in a $\beta$ configuration. As an anomer of $\beta$-nucleoside, $\alpha$-nucleoside is extremely rare in nature. Because of their unique and interesting properties such as high stability, specific parallel double-stranded structure and some other biochemical properties, $\alpha$-nucleosides have attracted wide attention. Various methods including but not limited to the mercuri procedure, fusion reaction and Vorbrüggen glycosylation have been used to synthesize $\alpha$-nucleosides and their derivatives. However, to the best of our knowledge, there is no review that has summarized these works. Therefore, we systematically review the discovery, synthesis, properties, and potential applications of $\alpha$-nucleosides in this article and look to provide a reference for subsequent studies in the coming years.
\end{abstract}

Received 24th February 2019

Accepted 29th April 2019

DOI: 10.1039/c9ra01399g

rsc.li/rsc-advances oligonucleotide can form a parallel double-stranded structure with the complementary $\beta$-oligonucleotide, show tolerance to or even inhibit some enzymes, and inhibit certain bacteria and tumors. Since their discovery, numerous studies of $\alpha$-nucleosides have been carried out and the characteristics of $\alpha$-nucleosides have gradually emerged. Here, we describe the discovery, extraction, synthesis, and separation of $\alpha$-nucleosides and their unique properties that differ from those of $\beta$-nucleosides.

\section{2. $\alpha$-Nucleosides and their derivatives found in nature}

As shown in Table 1, $\alpha$-nucleosides are extremely rare in nature, with only a few $\alpha$-anomers of nucleoside or nucleoside derivatives having been reported. In 1955, an $\alpha$-nucleoside derivative was first discovered in diphosphopyridine nucleotide (DPN), now known as nicotinamide adenine dinucleotide (NAD). Kaplan $^{2}$ et al. found that although DPN activity was destroyed by DPNase treatment, there was still a reaction with cyanide. Thus, they separated the cyanide-reacting material by column chromatography followed by acidic acetone precipitation and named this fraction as the "DPN isomer". Optical rotation tests showed that the DPN isomer differed from "normal" DPN in its nicotinamide glycosidic linkage; the DPN isomer showed a positive rotation, while "normal" DPN showed a negative rotation. They first proposed the concept of the $\alpha$-anomer. After that, in 1965, Suzuki ${ }^{3}$ et al. detected $\alpha$-NAD, $\alpha$-NADP, $\alpha$-nicotinic acid mononucleotide, and $\alpha$-nicotinic acid adenine dinucleotide in Azotobacter vinelandii. Besides, in 1963, Bonnett ${ }^{4}$ et al. found that 5,6-dimethyl-1- $\alpha$-D-ribofuranosyl benzimidazole- $3^{\prime}$ phosphate was a structural unit in vitamin $\mathrm{B}_{12}$. Additionally, in 1965, Gassen ${ }^{5}$ et al. used formic acid gradient elution to obtain a mixture of mononucleotides, which included $\alpha$-cytidine, from 


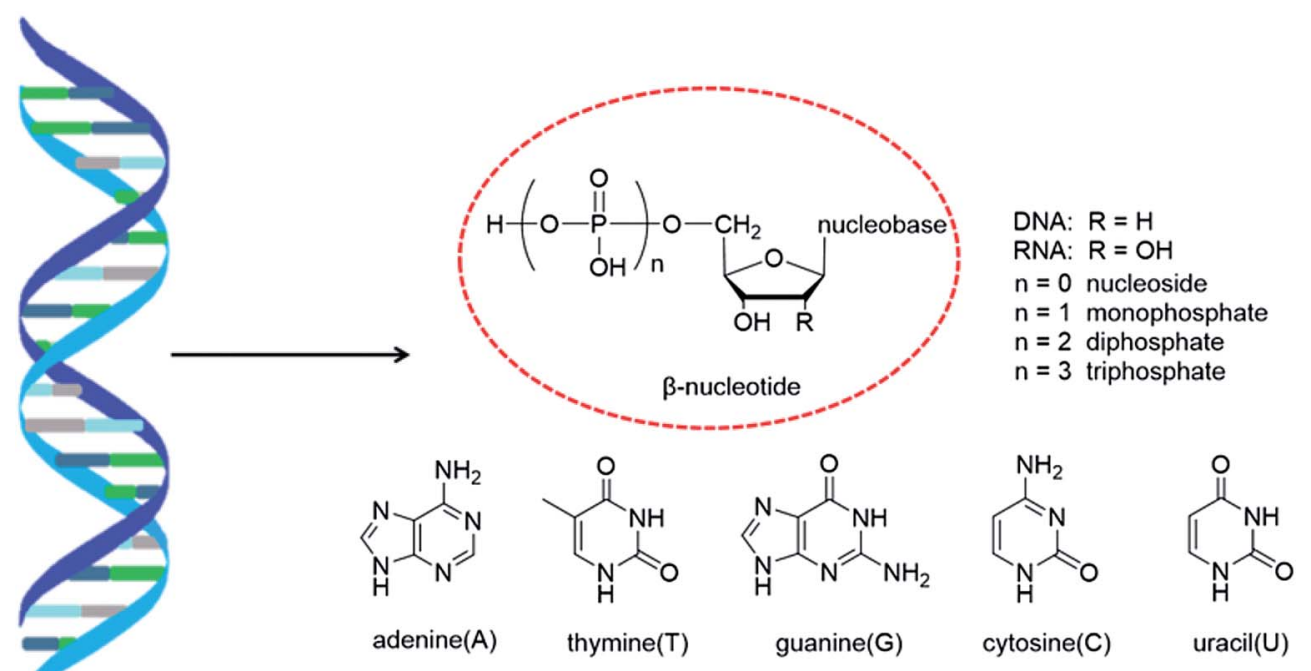

Fig. 1 Double helix structure of DNA or RNA and its components: nucleotides.

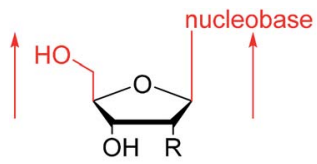

1a-e

$\beta$-nucleoside

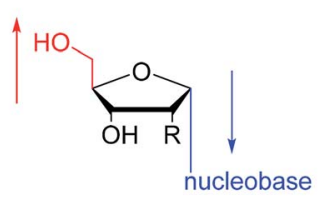

2a-e

a-nucleoside
Fig. 2 Configuration of $\beta$-nucleosides and $\alpha$-nucleosides.

a hydrolysate of yeast RNA on a Dowex-1 X2 column. Furthermore, after hydrolysis of the corrinoid factor $\mathrm{Cx}$ from Propionibacterium shermanii with cerous hydroxide, Dinglinger ${ }^{6}$ et al. isolated $\alpha$-adenosine by column chromatography in 1971 . These are the first reports of $\alpha$-anomers in naturally occurring nucleosides.

\section{Synthesis of various $\alpha$-nucleosides}

Although $\alpha$-nucleosides and their derivatives are rare in nature, they have recently received attention from researchers. To study their properties in detail and evaluate their application potential, various methods have been developed to chemically synthesize $\alpha$-nucleosides. Here, we mainly summarize the first methods developed for synthesizing various $\alpha$-nucleosides, such as $\alpha-\mathrm{A} / \mathrm{dA}, \alpha-\mathrm{rT} / \mathrm{T}, \alpha-\mathrm{U} / \mathrm{dU}, \alpha-\mathrm{G} / \mathrm{dG}$, and $\alpha-\mathrm{C} / \mathrm{dC}$. Additionally, interesting synthetic methods will be described.

\section{1. $\quad \alpha-\mathrm{A} \& \alpha-\mathrm{dA}$}

As shown in Fig. 3, Wright $^{7}$ et al. first proposed the chemical synthesis method for $\alpha$-adenosine in 1958, which was also the first synthesis of $\alpha$-nucleosides. Adopting the classic mercuri procedure, they used 5-O-benzoyl-D-ribofuranosyl bromide 2,3cyclic carbonate to condense with chloromercuri-6benzamidopurine, followed by removal of the protecting group to obtain $\beta$-adenosine and $\alpha$-adenosine at yields of $15 \%$ and $24 \%$, respectively. After that, in 1967, Schramm $^{8}$ et al. reported a new method for synthesizing $\alpha$-adenosine. After heating a mixture of ribose, adenine, and phenyl polyphosphate at $100{ }^{\circ} \mathrm{C}$ for $3 \mathrm{~min}$ in the presence of protons provided by concentrated $\mathrm{HCl}$, they directly obtained a mixed product of adenosine, including common $\beta$-adenosine and its $\alpha$-anomer at $20 \%$ yield. Under similar conditions, they obtained $40 \%$ yield of $\beta$ - and $\alpha$-deoxyadenosine. Using unprotected ribose and

Table $1 \alpha$-Nucleosides and their derivatives found in nature

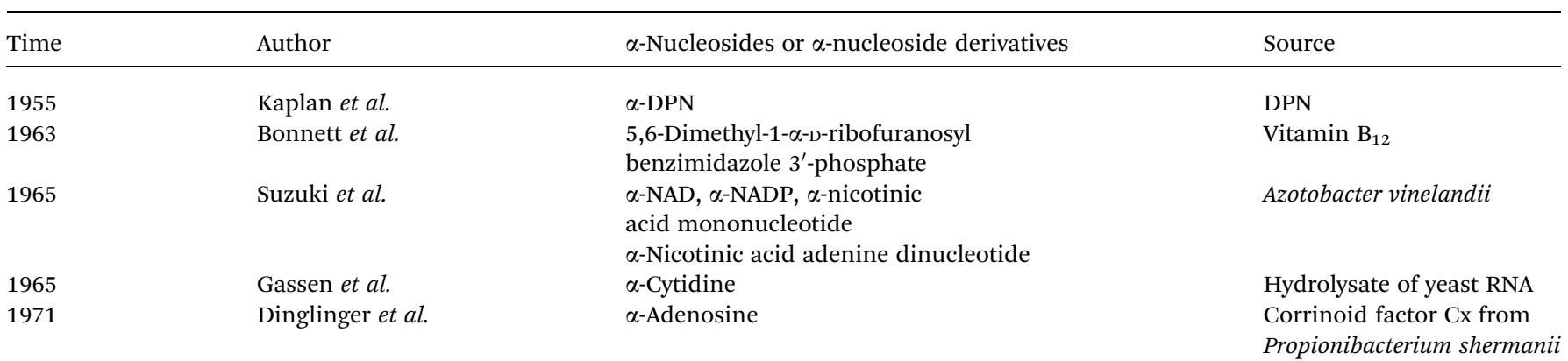




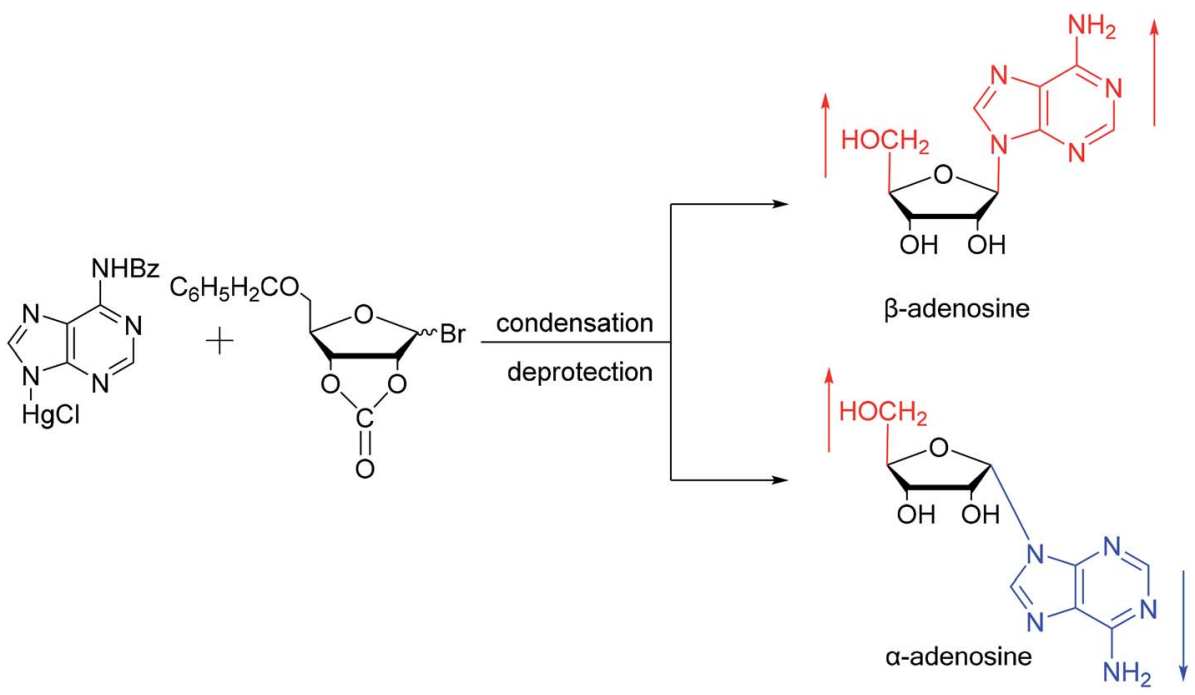

Fig. 3 First synthesis of $\alpha$-adenosine.

nucleobase avoids the need to prepare intermediates, making this new method simpler and faster than traditional methods. The new method also avoids the stereochemical limitations of acylated sugars and makes it easier to prepare $\alpha$-anomers.

Similarly, using the mercuri procedure, $\mathrm{Ness}^{9}$ et al. first proposed the synthesis of $\alpha$-deoxyadenosine in 1960 (Fig. 4). They used 2-deoxy-5-O- $p$-nitrobenzoyl-D-ribose diisobutyl dithioacetal as a starting material, which was converted to 2deoxy-3,5-di-O- -nitrobenzoyl-D-ribosyl chloride through a series of reactions, and then condensed with chloromercuri-6benzamidopurine in dimethyl sulfoxide solution. After deprotection, $\beta$-deoxyadenosine and its $\alpha$-anomer were obtained at $10 \%$ and $19 \%$ yields, respectively. However, when mercuri procedure is used to synthesize nucleosides, contamination with mercury ions affect the biological functions of nucleosides, ${ }^{10}$ and thus Robins ${ }^{11}$ et al. attempted to synthesize nucleosides using a new method to avoid using mercury. The main starting material is 1,3,5-tri-O-acetyl-2-deoxy-D-ribofuranose, which was obtained by treating 6 -acetamido-9- $\left(3^{\prime} 5^{\prime}\right.$-di- $O$-acetyl$2^{\prime}$-deoxy- $\beta$-D-ribofuranosyl)purine with acetic acid and acetic anhydride at $100{ }^{\circ} \mathrm{C}$, the obtained nucleoside derivative was mainly in the $\alpha$-configuration. Then fused with 2,6-dichloropurine, and after treatment with methanolic ammonia and catalytic dehalogenation, $\alpha$-dA is synthesized. In addition, various reported $\alpha$-adenosine derivatives are shown in Table 2 .

\section{2. $\alpha-\mathrm{rT} / \mathrm{U} \& \alpha-\mathrm{T} / \mathrm{dU}$}

In 1964, Nishimura ${ }^{19}$ et al. used trimethylsilyl groups to protect nucleobases, followed by condensation with tribenzoylribofuranosyl chloride, an acyl halo sugar. After deacylation, they obtained nucleosides corresponding to the nucleobases. They found that when this method was used to synthesize uridine and thymidine, the corresponding $\alpha$-anomer could be separated from the product (Fig. 5). That is the first available report of artificial synthesis of $\alpha-r \mathrm{~T} / \mathrm{U}$.

While exploring the stereoselective synthesis of $\alpha$-nucleosides, Aoyama ${ }^{20}$ proposed a method for synthesizing deoxyuridine and deoxythymidine in a stereoselective manner in 1987, including the $\beta$ - and $\alpha$-anomers, as illustrated in Fig. 6 . In the condensation reaction of 5-substituted-2,4-di(trimethylsilyloxy) pyrimidines and 3,5-di( $O$ - $p$-chlorobenzoyl)-2-deoxy- $\alpha$-D-ribofuranosyl chloride, they found that when Brønsted acid ( $p$ -

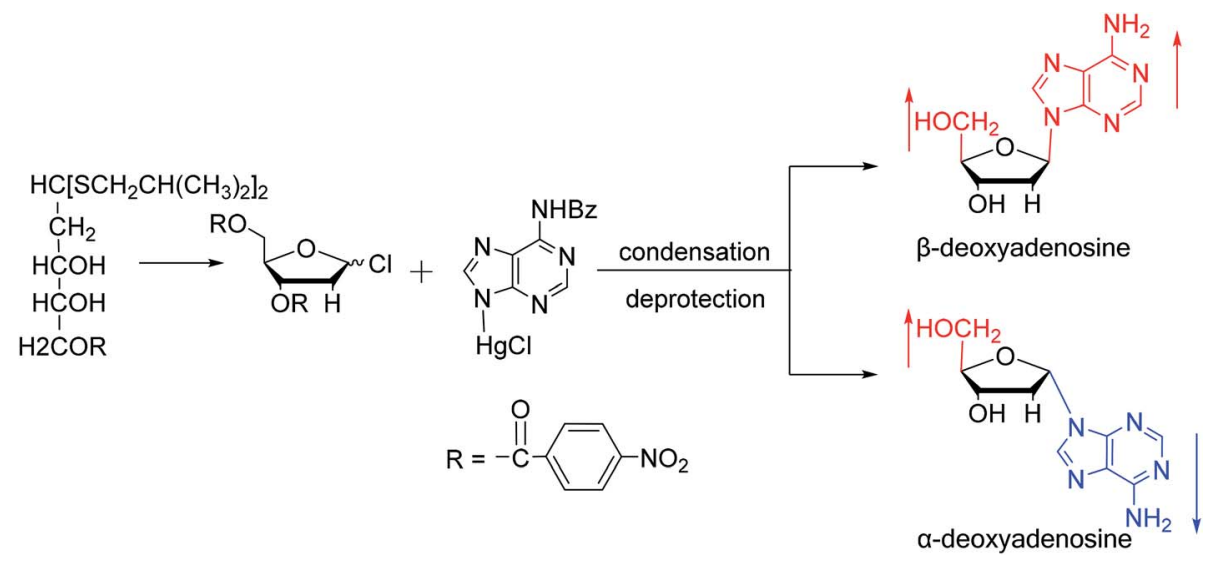

Fig. 4 First synthesis of $\alpha$-deoxyadenosine. 
Table 2 Some $\alpha$-adenosine derivatives

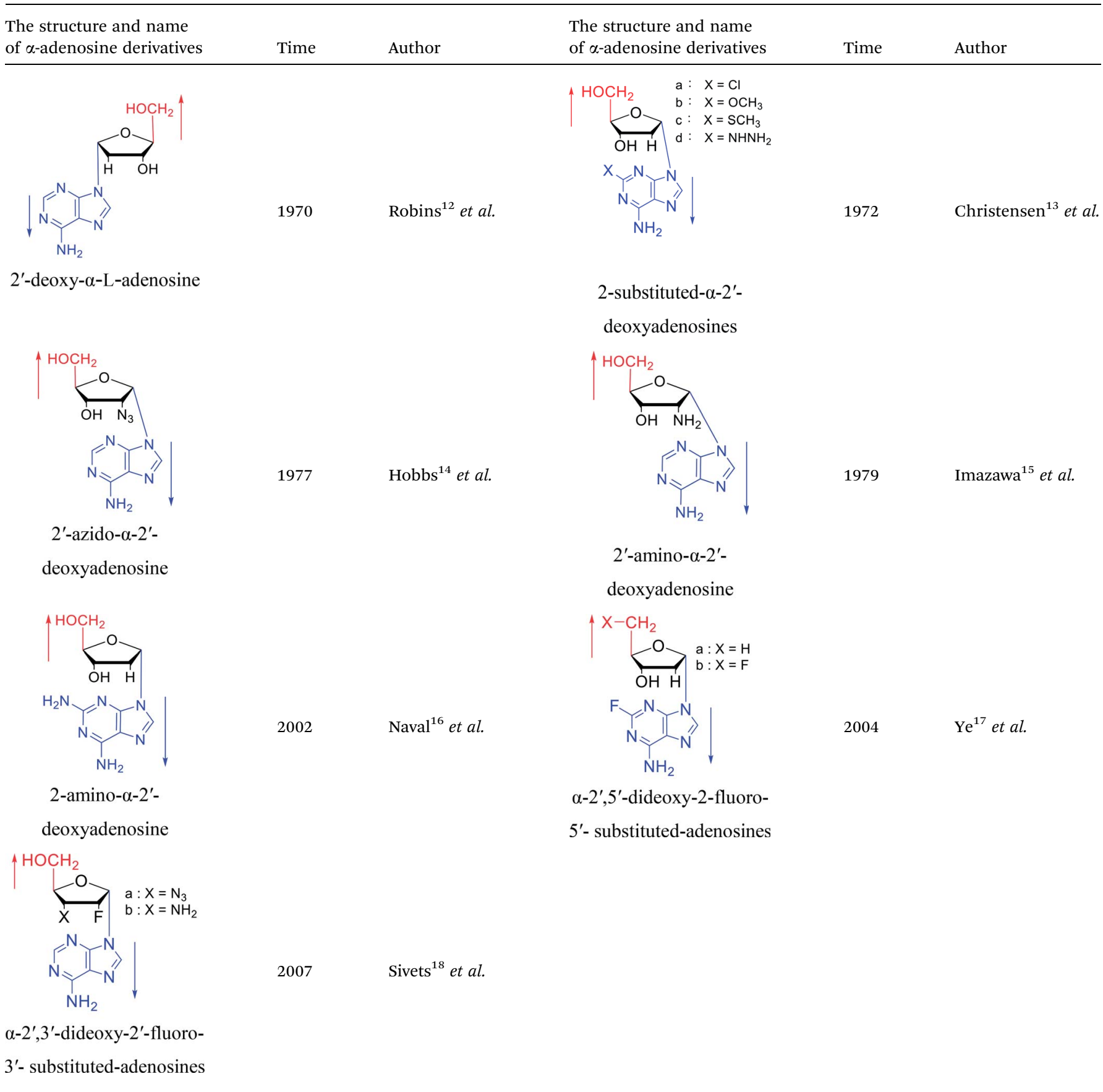

nitrophenol) was present, $\beta$-T/dU was stereoselectively synthesized in $96 \%$ yield; and on this basis, when organic bases (pyridine) were added, $\alpha-\mathrm{T} / \mathrm{dU}$ was formed in approximately $70 \%$ yield.

Using a similar method, Shimizu ${ }^{21}$ et al. used trimethylsilyl and benzoyl as protective groups, in a series of reactions, they first synthesized $5^{\prime}$-phosphate- $\alpha$-D-cytidine, and with similar conditions, $5^{\prime}$-phosphate- $\alpha$-L-uridine and $5^{\prime}$-phosphate- $\alpha$-Lthymidine was also synthesized at a ratio of $\alpha: \beta$ of approximately $2: 1$. Besides, we summarized the $\alpha$-uridine/thymidine derivatives in Table 3 .

\section{3. $\quad \alpha-G \& \alpha-d G$}

A method for stereoselective synthesis of $\alpha$-guanosine was first proposed by Gosselin ${ }^{45}$ et al. in 1990 . They used $\alpha$-D-ribofuranothioxooxazolidine as a starting material, after four-step reaction involving tert-butyldimethylsilyl chloride (TBDMSCl), RANEY® $\mathrm{Ni}, \mathrm{NH}_{2} \mathrm{CH}(\mathrm{CN}) \mathrm{CONH}_{2}$ and tetrabutylammonium fluoride (TBAF) respectively, they transformed it to $1-\alpha-\mathrm{D}^{-}$ ribofuranosyl-4-carbamoyl-5-aminoimidazole, which was treated with sodium methylxanthate at $180{ }^{\circ} \mathrm{C}$. After oxidized with hydrogen peroxide and amination with ammonia, they obtained $\alpha$-guanosine in a $6.6 \%$ yield (Fig. 7 ). Although there 


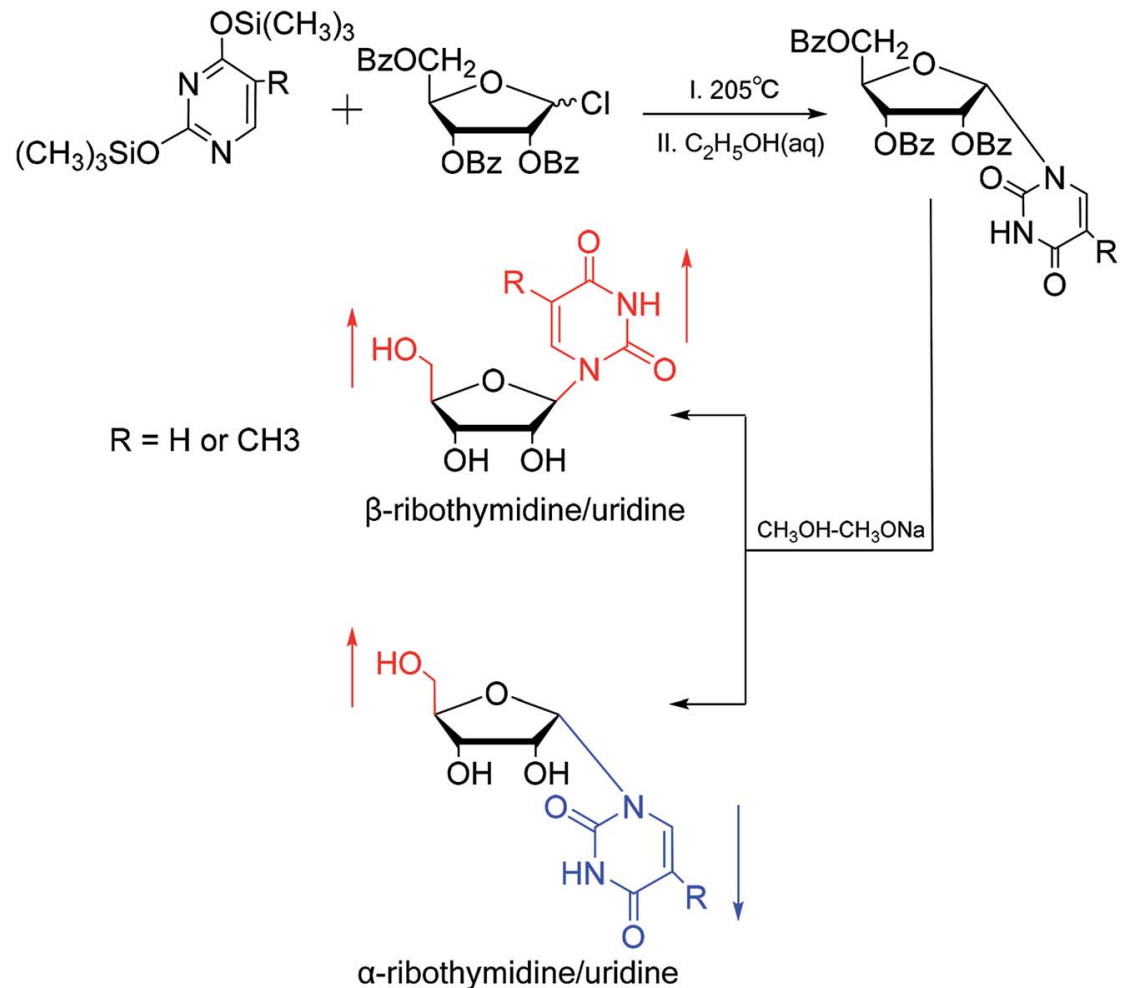

Fig. 5 First synthesis of $\alpha$-ribothymidine/uridine.

have been several reports on the synthesis of $\alpha$-guanosine, ${ }^{46,47}$ it is typically produced only as a by-product of other reactions. Therefore, we consider that this was the first synthesis of $\alpha$ guanosine.

Believing that some of the previous methods are somewhat unsuited for the preparation of deoxyguanosines, in 1969, Robins $^{48}$ et al. first reported a fusion procedure to synthesize $\alpha$ deoxyguanosine, which shown in Fig. 8. They used 2-fluoro-6benzyloxypurine and 1,3,5-tri-O-acetyl-2-deoxyribose as raw materials for acid-catalyzed fusion reactions, and the obtained product was treated with methanol ammonia at $80^{\circ} \mathrm{C}$. After catalytic hydrogenation by palladium, they obtained $\beta$-deoxyguanosine and $\alpha$-deoxyguanosine in $14 \%$ and $16 \%$ yields, respectively. In addition, in 1993, Morvan ${ }^{49}$ et al. proposed two new methods for the synthesis of $\alpha$-deoxyguanosine derivatives. One method used 2-N-palmitoyl-guanine and $3^{\prime} 5^{\prime}$-di-O-acetyl-4$N$-benzoyl-2'-deoxycytidine as starting materials to carry out transglycosylation reaction in the presence of Lewis acid and

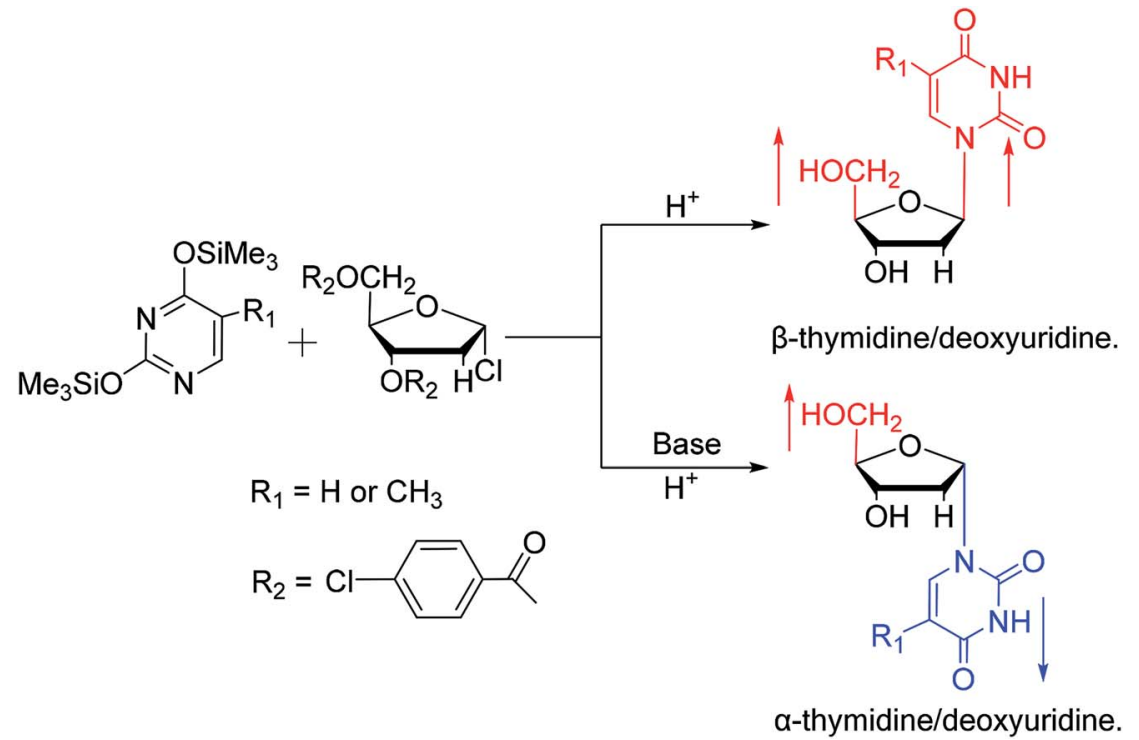

Fig. 6 First synthesis of $\alpha$-thymidine/deoxyuridine. 
Table 3 Some $\alpha$-uridine/thymidine derivatives

The structure and name of $\alpha$-uridine/thymidine

derivatives

$\uparrow \mathrm{HOCH}_{2}$<smiles>OCCOCC(O)CO</smiles><smiles></smiles>

1964

1969

5-s-substituted- $\alpha-2^{\prime}-$

deoxyuridines.

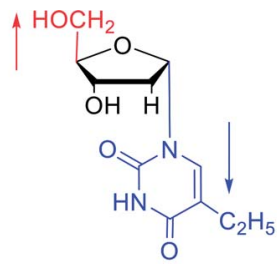

5-ethyl- $\alpha-2$ '-deoxyuridine

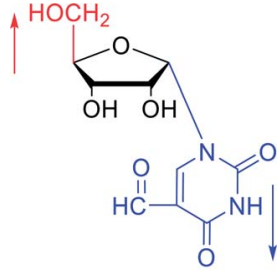

$\alpha$-5-formyluridine<smiles>C#Cc1cn(C2COC3OC2CC3O)c(=O)[nH]c1=O</smiles>

5-ethynyl- $\alpha-2$ -

deoxyuridine
The structure and name of $\alpha$-uridine/thymidine derivatives

Time

Author

1966

Ryan $^{23}$ et al.

5-trifluoromethyl- $\alpha-2^{\prime}$ -

deoxyuridine

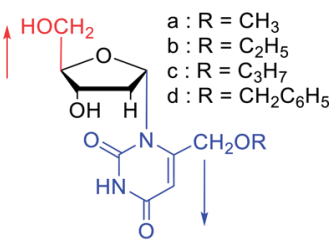

Ether derivatives of 5-

hydroxymethyl- $\alpha-2^{\prime}$

deoxyuridines

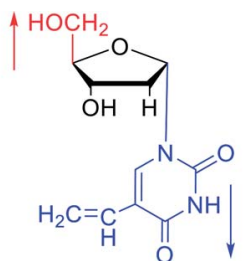

1975

Sharma $^{27}$ et al.

5-vinyl- $\alpha-2$ '-deoxyuridine<smiles>O=c1ccn(CCOCCO)c(=O)[nH]1</smiles>

1977

Brink $^{29}$ et al.

2'-C-nitromethyl- $\alpha-2$ '-

deoxyuridine

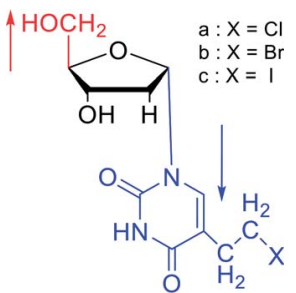

1985

Griengl $^{31}$ et al. 5-haloalkyl- $\alpha-2$ -

deoxyuridines 
Table 3 (Contd.)

The structure and name of $\alpha$-uridine/thymidine

derivatives<smiles>O=c1[nH]c(=O)n(C2COC(CO)C(O)C2O)cc1C=C(F)F</smiles>

5-(2,2-difluorovinyl)- $\alpha-2$ 'deoxyuridine

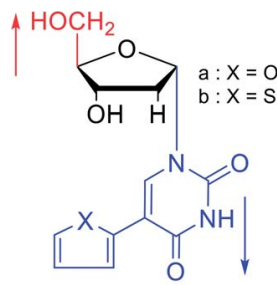

5-furan/thien- $\alpha-2$ 'deoxyuridines

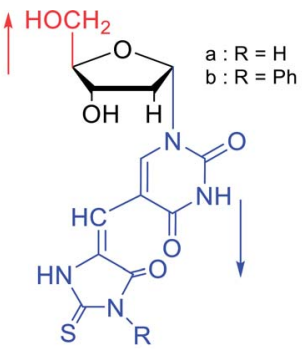

1994

5-methylene-2-thiohydant oin-3-substituted- $\alpha-2^{\prime}-$

deoxyuridines<smiles>O=c1ccn(C2COCC2O)c(=O)[nH]1</smiles>

1997 $\operatorname{Diaz}^{37}$ et al.
1987 Bobek $^{32}$ et al.

Wigerinck $^{33}$ et al.

Elbarbary $^{35}$ et al.
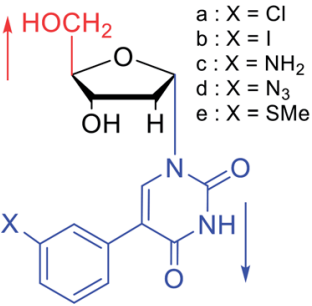

1996

Wellmar $^{36}$ et al.
1987

Aoyama $^{20}$ 5-substituted-2'-

deoxyuridines<smiles>O=c1[nH]c(=S)n(C2C3OC(O)C(O3)C2O)cc1F</smiles>

1993

Bretner $^{34}$ et al.

5-fluoro-2-thio- $\alpha-2$ '-

deoxyuridine $\alpha$-uridine/thymidine

derivatives

5-(3-substituted-phenyl)- $\alpha$

-2 -deoxyuridines

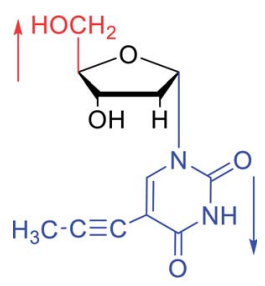

5-propynyl- $\alpha-2$ -

deoxyuridine

deoxyuridine 
Table 3 (Contd.)

The structure and name of $\alpha$-uridine/thymidine

derivatives dideoxyuridine

The structure and name of

$\alpha$-uridine/thymidine

derivatives
Time

Author 5-amino- $\alpha-2$ ', 3'-

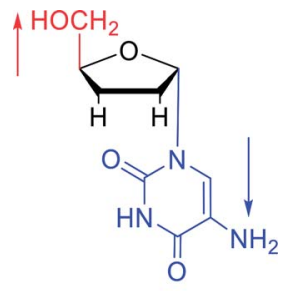<smiles>N#C/C=C/c1cn(C2COC(CO)(CO)CC2O)c(=O)[nH]c1=O</smiles>

5-cyanovinyl- $\alpha-2$ -

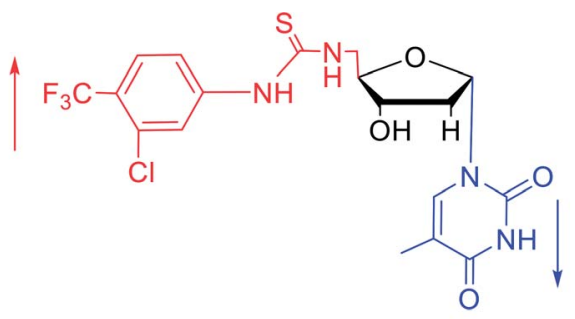

5'-(3-trifluoromethyl-4-chlorophenyl)thiourea- $\alpha$-2'-deoxythymidine<smiles>Cc1cn(C2C3CCC2(CO)OC3N)c(=O)[nH]c1=O</smiles>

3'-azido- $\alpha-2$ ', $3^{\prime}-$

dideoxythymidine
2010

$\mathrm{Cui}^{42}$ et al.<smiles>Cc1cn(C2COC3OCC2CC3C(=O)NC(=O)Nc2ccc(Oc3ccccc3Cl)cc2)c(=O)[nH]c1=O</smiles>

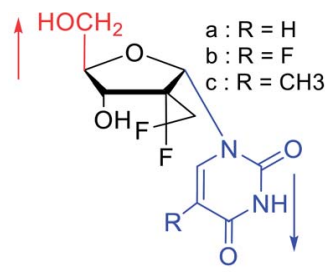

5-substituted-2'-

spirodiflurocyclopropyl- $\alpha$

-2 '-deoxyuridines
2016

$\mathrm{Liu}^{43}$ et al. silylating agent, and after deprotection, $2-N$-palmitoyl- $\alpha$-deoxyguanosine is obtained. In the second method, silylated guanine and 1-O-acetyl-3,5-di-O- $p$-nitrobenzoyl-2-deoxyribose were glycosylated under phase transfer conditions. And with deprotection after acylation of guanine, they finally obtained 2- $\mathrm{N}$ isobutyryl- $\alpha$-deoxyguanosine.

Furthermore, due to steric hindrance, as illustrated in Table 4, $\alpha$-guanosine derivatives are rarer than other nucleosides.

\section{4. $\alpha-\mathrm{C} \& \alpha-\mathrm{dC}$}

Sanchez ${ }^{52}$ et al. first synthesized $\alpha$-cytidine in 1970 (Fig. 9). They reacted $\mathrm{D}$-ribose and cyanamide in aqueous solution to give the corresponding aminooxazoline derivative. The derivative was reacted with cyanoacetylene to synthesize $\alpha$-cytidine for the first time. Due to found that the previous synthesis method of $\alpha$ nucleoside had the problem of stereo selection, in 1994, Sawai $^{53}$ et al. improved this method to stereoselectively synthesize $\alpha$ - 


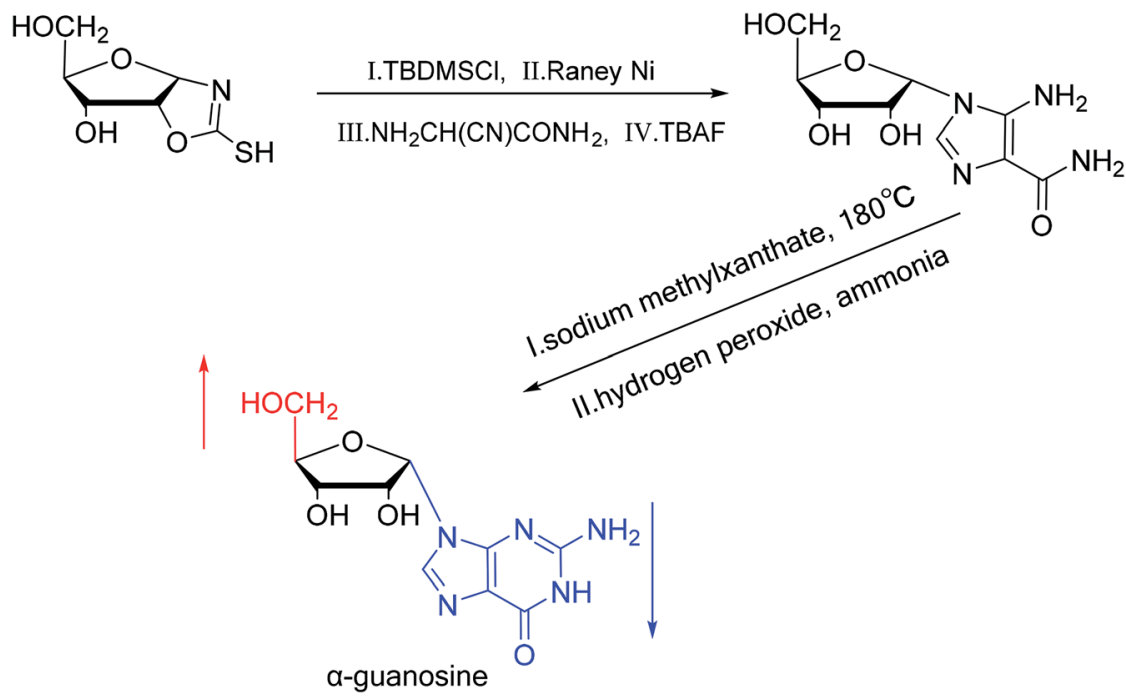

Fig. 7 First synthesis of $\alpha$-guanosine.

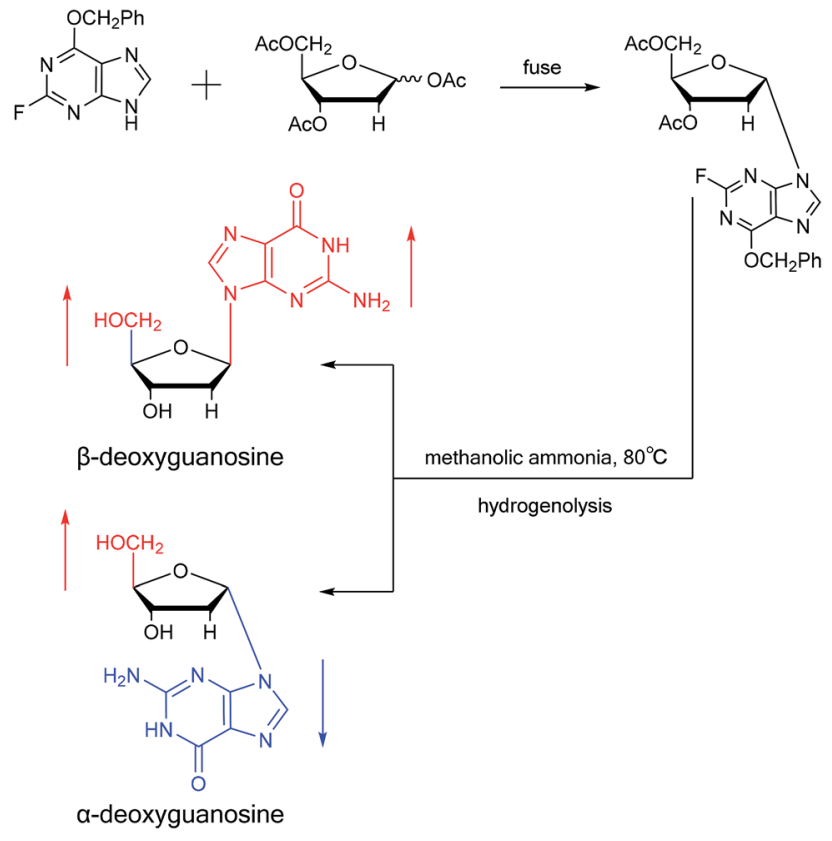

Fig. 8 First synthesis of $\alpha$-deoxyguanosine.

nucleosides based on Sanchez et al.'s research. They not only synthesized $\alpha$-cytidine and $\alpha$-deoxycytidine, but also obtained $\alpha$ thymidine in $10 \%$ yield. In this process, no $\beta$-nucleosides were synthesized.

Additionally, in 1961, as illustrated in Fig. 10, Fox $^{54}$ et al. reported the synthesis of $\alpha$-deoxycytidine using the mercuri procedure. They condensed 3,5-di-O-( $p$-chlorobenzoyl)-2-deoxyD-ribosyl chloride with mercuri- $N$-acetylcytosine to obtain deoxycytidine derivatives. After deacylation with alcoholicammonia, the $\alpha$ - and $\beta$-deoxynucleosides were synthesized, which was the first synthetic $\alpha$-deoxycytidine. The $\alpha$-cytidine derivatives are summarized in Table 5.
Interestingly, in 1978 , Imazawa ${ }^{59}$ et al. proposed a novel method for the synthesis of $\alpha$-nucleoside derivatives. They used trimethylsilyl trifluoromethanesul-fonate (TMS-triflate) and bis(trimethylsilyl)-acetamide (BSA) as catalysts and reacted $3^{\prime}$ azido-3'-deoxy-5'-O-acetylthymidine with silylated $N^{6}$-octanoyladenine to obtain $\alpha$ - $3^{\prime}$-azido- $2^{\prime}, 3^{\prime}$-dideoxyadenosine. Through a similar reaction, they also obtained the $\alpha$-anomer of 9-( $3^{\prime}-$ azido-2' ${ }^{\prime} 3^{\prime}$-dideoxy-D-ribofuranosyl)guanine. Referring to this transglycosylation reaction, Yamaguchi ${ }^{60}$ et al. reported a new method for the synthesis of $\alpha$-nucleosides in 1984 (Fig. 11). They used TMS-triflate and BSA to induce the self-anomerization of $\beta$ nucleosides to $\alpha$-nucleosides. Specifically, they reacted $3^{\prime}, 5^{\prime}$-di$O$-acetyl- $N_{4}$-benzoyl-2'-deoxycytidine with TMS-triflate and BSA in dry acetonitrile at $70{ }^{\circ} \mathrm{C}$. After saponification, $\alpha$-deoxycytidine was synthesized in $41 \%$ yield. Using a similar synthetic pathway, they also synthesized $\alpha$-deoxyadenosine and $\alpha$-deoxythymidine at yields of $33 \%$ and $28 \%$, respectively. Referring to this reaction, in 2002, Sato ${ }^{61}$ et al. used TMS-triflate to treat $\beta$ thymidine derivatives in acetonitrile solution, after deprotection, they achieved epimerization of $\beta$-thymidine and obtained $\alpha$-thymidine in an overall yield of $50 \%$ from $\beta$-thymidine.

In fact, self-anomerization occurring in nucleoside derivatives are not rare. For example, in 1976, Armstrong ${ }^{28}$ et al. found that after treatment with strong base, part of the $\beta$-5-formyluridines were anomeric to $\alpha$-5-formyluridine. And in 1986, Seela $^{62}$ et al. accidentally found that after treatment with $1 \mathrm{M}$ aqueous hydrochloric acid, $\beta$-2-deoxy-2-methoxy tubercidin was isomerized by a transglycosylation reaction to obtain its $\alpha$ anomer in a yield of $13 \%$. Similarly, in 1993 , Ward $^{63}$ et al. pointed out that when a mixture of sulfuric acid and acetic anhydride was added to a solution of $\beta-3^{\prime}, 5^{\prime}$-di-O-acetylthymidine in acetonitrile, rapid isomerization occurred to establish a balance of $\alpha: \beta=2: 1$ in a few minutes. They speculated that this catalytic effect was caused by the $\mathrm{CH}_{3} \mathrm{CO}-$ group.

Furthermore, classic Vorbrüggen glycosylation can also be used to synthesize $\alpha$-nucleosides. In 1994 , Janardhanam ${ }^{64}$ et al. 
Table 4 Some $\alpha$-guanosine derivatives

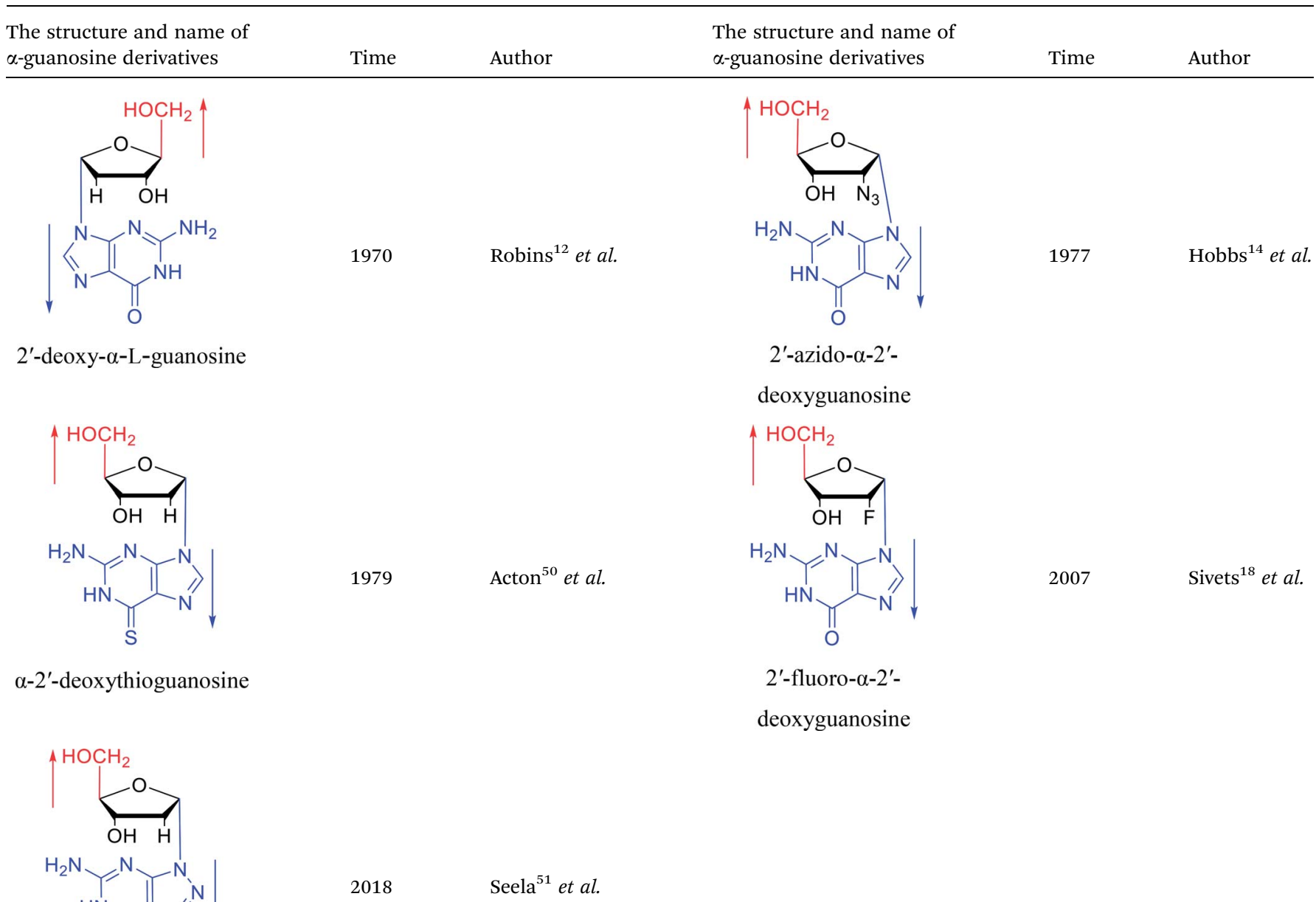

8 -aza- $\alpha$-2'-deoxyguanosine

protected the nucleobase with trimethylsilyl and protected deoxyribose with $p$-methylbenzoyl. They adopted Vorbrüggen glycosylation to synthesize all five $\alpha$-nucleoside or $\alpha$-nucleoside
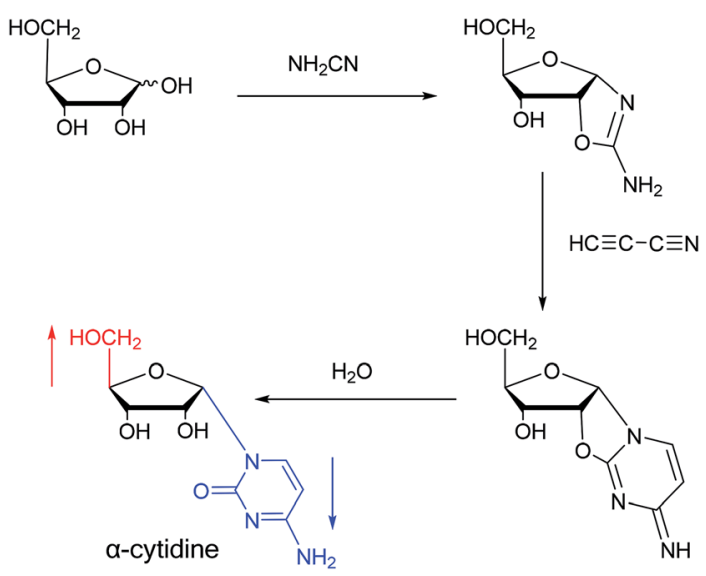

derivatives by the catalysis of $\mathrm{SnCl}_{4}$. At the same time, they found that carrying the reaction out in the presence of ten equivalents of $\mathrm{SnCl}_{4}$ resulted in the highest production of $\alpha$ nucleoside $(\alpha: \beta=75: 25)$. Additionally, in 1997, as shown in Fig. 12, Wang ${ }^{65}$ et al. showed that Vorbrüggen glycosylation was guided by benzoate at the $\mathrm{C} 2$ position of arabinose to achieve stereoselective synthesis of $\alpha$-nucleosides derivatives. After photoinduced electron-transfer (PET) deoxygenation and deprotection, they synthesized $\alpha-\mathrm{dA}, \mathrm{T}, \mathrm{dG}$ and dC.

As we talk about stereoselective synthesis, it should be noted that in 1969, when Kotick $^{\mathbf{2 4}}$ et al. synthesized 5-s-substituted- $\alpha$ 2 -deoxyuridines, they found that when trimethylsilyl chloride was present during the condensation process, it was more favorable for the synthesis of $\alpha$-uridine derivatives, while under the condition of removing trimethylsilyl chloride, the main product was the $\beta$-configuration. And they suspected that this might be caused by the exchange of chlorides.

Notably, Garcia ${ }^{\mathbf{6 6}}$ et al. found that Pseudomonas cepacia lipase (PSL-C) is highly chemo- and regio-selective for the $3^{\prime}$ position of

Fig. 9 First synthesis of $\alpha$-cytidine. 


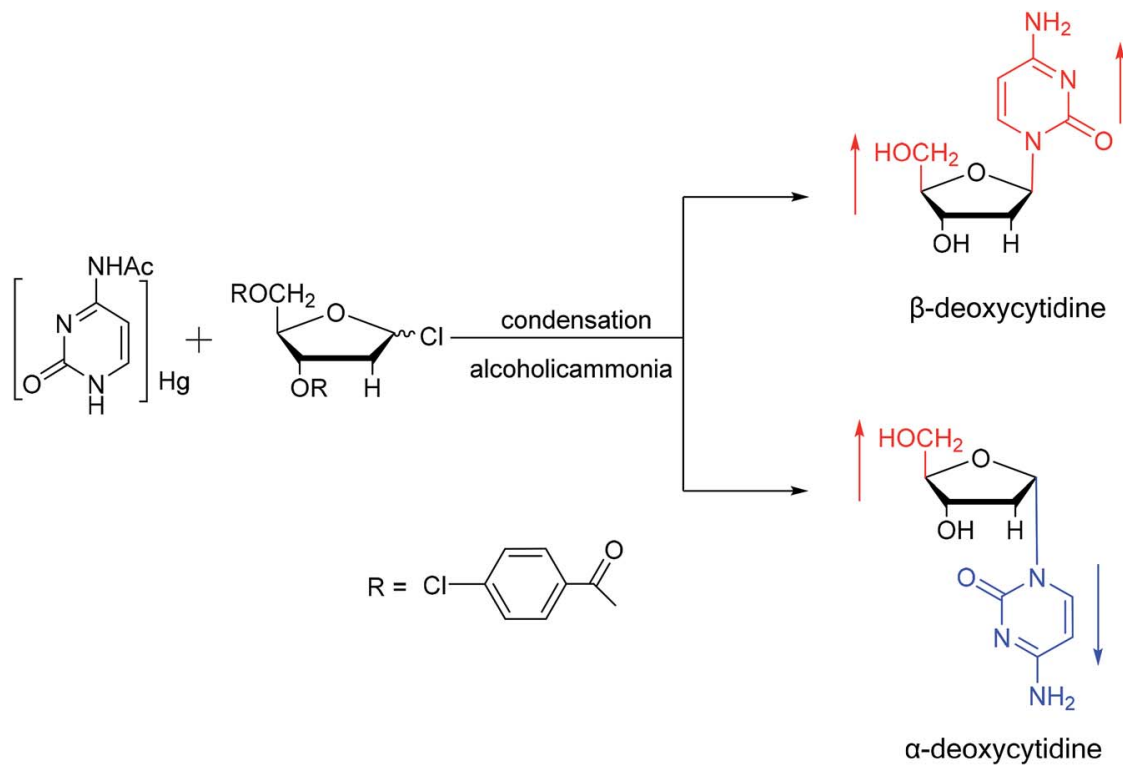

Fig. 10 First synthesis of $\alpha$-deoxycytidine.

the $\beta$-2'-deoxynucleoside derivative, displaying opposite selectivity for the $5^{\prime}$-position of the corresponding $\alpha$-anomer. They considered this to be an effective method for separating $\alpha$ and $\beta$ 2 -deoxynucleosides. In fact, they had separated an $\alpha$ and $\beta$ mixture of thymidine derivatives from industrial waste streams in 2006.

In summary, as shown in Fig. 13, we mainly compiled the first reports of the syntheses of various $\alpha$-nucleosides, it was clear that $\alpha$ nucleosides were originally only by-products of the nucleoside synthesis process, but with the discovery of various unique properties of $\alpha$-nucleosides, which will be discussed in the next section, the synthesis of $\alpha$-nucleosides has also begun to attract the attention of researchers. In the early stage of $\alpha$-nucleoside synthesis research, as the above-mentioned first synthesis of $\alpha-\mathrm{A} / \mathrm{dA}$, the main method is condensation reaction under mercury protection. After realizing that the presence of mercury affects the biological properties of nucleosides, researchers have begun to replace mercury with other protecting groups such as acetyl, benzoyl, halogen, and so on. With the deepening of the study, the researchers found that under the function of certain chemicals such as TMS-triflate and BSA, the selfanomerization of $\beta$-nucleosides can be achieved to obtain the corresponding $\alpha$-nucleosides. Later, since the previous synthetic methods of $\alpha$-nucleoside were found to generally obtain a large number of $\beta$-nucleosides as by-products while synthesizing $\alpha$ nucleosides, the researchers proposed some methods like oxazoline method and Vorbrüggen glycosylation to stereoselectively synthesize $\alpha$-nucleosides. Unfortunately, to date, there is no systematic method for synthesizing all $\alpha$-nucleosides, which we believe should be one of the directions for future research.

\section{Property and application of $\alpha-$ nucleosides}

While synthesizing $\alpha$-nucleosides, researchers also investigated their properties. Because of the unique structure of $\alpha$ - nucleosides, some of their properties differ from those of $\beta$ nucleoside apart from their optical rotation. Although nearly all studies are in the laboratory stage, it is undeniable that $\alpha$ nucleosides have potential application value in some fields. Here, we summarize the main unique properties of $\alpha$-nucleosides, for example, their higher stability compared to the $\beta$ anomer, specific parallel double-stranded structure of $\alpha$ $\beta$ duplex, inhibition of tumors, bacteria and malaria parasites, and other biological properties.

\subsection{Enzymatic stability of $\alpha$ nucleosides and $\alpha$ - oligonucleotides}

It is generally thought that $\alpha$-nucleosides are more stable than natural beta nucleosides, as indicated by their resistance to various enzymes. In 1961, when synthesizing $2^{\prime}$-deoxycytidine and its $\alpha$-anomer, Fox $^{54}$ et al. found that when $2^{\prime}$-deoxycytidine was deaminated and enzymatically hydrolyzed into uracil by nucleoside deaminases and nucleosidases in resting cell suspensions of Escherichia coli B, its $\alpha$-anomer was inert to these reactions. Similarly, the $\alpha$-anomer of thymidine was resistant to glycosyl cleavage by E. coli B nucleosidases. In 2008 , Hatano ${ }^{67}$ et al. found that $\alpha$-thymidine was not destroyed when $\beta$-thymidine and its derivatives were converted to the 1-phosphate form and a free thymine nucleobase under the function of thymidine phosphorylase (TP). They suggested that this was because the nucleobase of the $\alpha$ form did not fit into the pocket of TP. And in 1974, Sequin ${ }^{68}$ et al. used four dinucleoside monophosphates $\beta \mathrm{T}-\beta \mathrm{T}, \alpha \mathrm{T}-\beta \mathrm{T}, \beta \mathrm{T}-\alpha \mathrm{T}$ and $\alpha \mathrm{T}-\alpha \mathrm{T}$ as substrates for snake venom phosphodiesterase and spleen phosphodiesterase. The results showed that although all four compounds are substrates for both enzymes, if enzymic attack occurred in the $\alpha$-nucleoside portion of the dinucleoside monophosphate, the rate of the hydrolysis was quite slow. In 1987, Morvan $^{69}$ et al. used $\mathrm{d}(\mathrm{CATGCG})$ as a substrate for endonucleases and exonucleases. The $\alpha$-hexamer remained nearly intact when the natural $\beta$ - 
Table 5 Some $\alpha$-cytidine derivatives

The structure and name of a-cytidine derivatives

( $\mathrm{HOCH}_{2}$<smiles></smiles>

5-fluoro- $\alpha-2$-deoxycytidine<smiles>COC</smiles><smiles>CCc1cn(C2C3CC4CC2C(C3)O4)c(=O)nc1N</smiles>

5-ethyl- $\alpha-2$ '-deoxycytidine

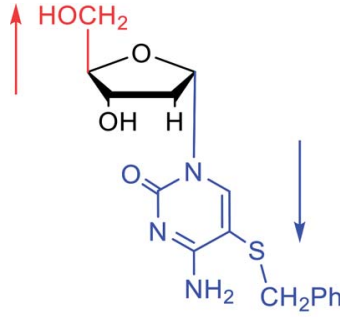

5 -sulfur substituted- $\alpha$ -

2'-deoxycytidine<smiles>[Y][Y]#[Y]=S</smiles>

5-aryl- $\alpha-2$-deoxycytidines<smiles>Nc1nc(=O)n(C2CC3COC2C3)cc1[N+](=O)[O-]</smiles>

5-nitro- $\alpha-23^{\prime}-$ dideoxycytidine

The structure and name of $\alpha$-cytidine derivatives

Time

Author

1966

Duschinsky $^{55}$ et al.

1983

Solan $^{57}$ et al.

1992

2003

Colacino $^{39}$ et al.<smiles>Cn1ccc(N)nc1=O</smiles>

3'-C-methyl- $\alpha-2$ '-

deoxycytidine

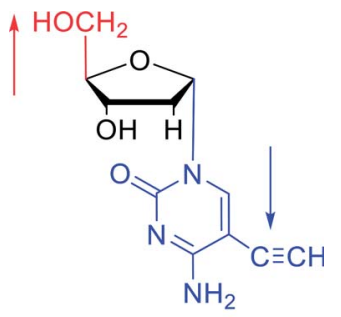

5-ethynyl- $\alpha-2$ -

deoxycytidine<smiles>Nc1nc(=O)n(C2C(CO)OC(CO)C2O)cc1C1CC1</smiles>

5-cyclopropyl- $\alpha-2$ deoxycytidine<smiles>[X]c1cn(C2[C@H](O)[C@H](C)O[C@H](CO)[C@H]2O)c(=O)nc1N</smiles>

5-nitro/amino- $\alpha-2$ '-

deoxycytidines

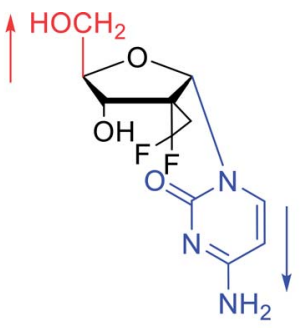

2 '-spirocyclopropyl- $\alpha-2$ 'deoxycytidine 

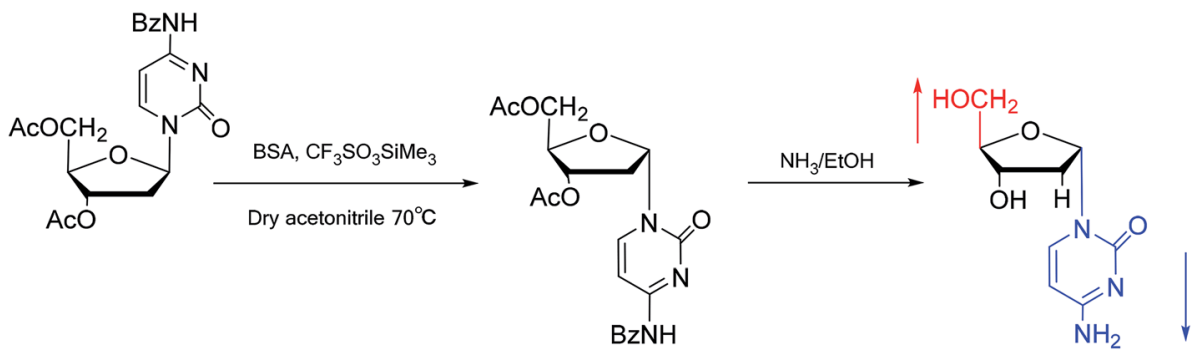

Fig. 11 Self-anomerization of $\beta$-nucleosides to $\alpha$-nucleosides.

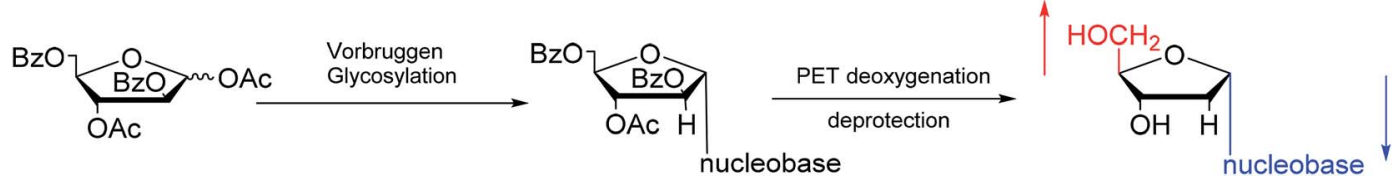

Fig. 12 Stereoselective synthesis of $\alpha$-nucleosides by Vorbrüggen glycosylation.

hexamer was completely degradated by nuclease $\mathrm{S} 1$ and calf spleen phosphodiesterase. Also in 1987, Thuong ${ }^{70}$ et al. showed that $\alpha$-oligothymidylates are much more resistant to endonucleases than their $\beta$ analogs, while additional protection against the corresponding exonuclease was provided by acridine incorporation. They suggested that this was because insertion of the acridine ring formed a miniduplex structure and provided additional binding energy, which strongly stabilized the double strand with a complementary sequence. In addition, since $\beta$-oligodeoxynucleotides (fully $\beta$-modified oligonucleotides) were rapidly destroyed by serum enzymes and degraded in cells, in 1988, Bacon ${ }^{71}$ et al. synthesized and studied the degradation process of $\alpha$-oligodeoxynucleotides (fully $\alpha$-modified oligonucleotides) in different media such as rabbit reticulocyte lysates. The results suggested that, in contrast to $\beta$ oligodeoxynucleotides, the degradation of $\alpha$-oligodeoxynucleotides in various media was quite slow, even without degradation, which indicated the strong enzyme stability of $\alpha$ oligodeoxynucleotides. Because of the resistance of $\alpha$-nucleosides and $\alpha$-oligonucleotides to these enzymes, they may be useful as gene control agents.

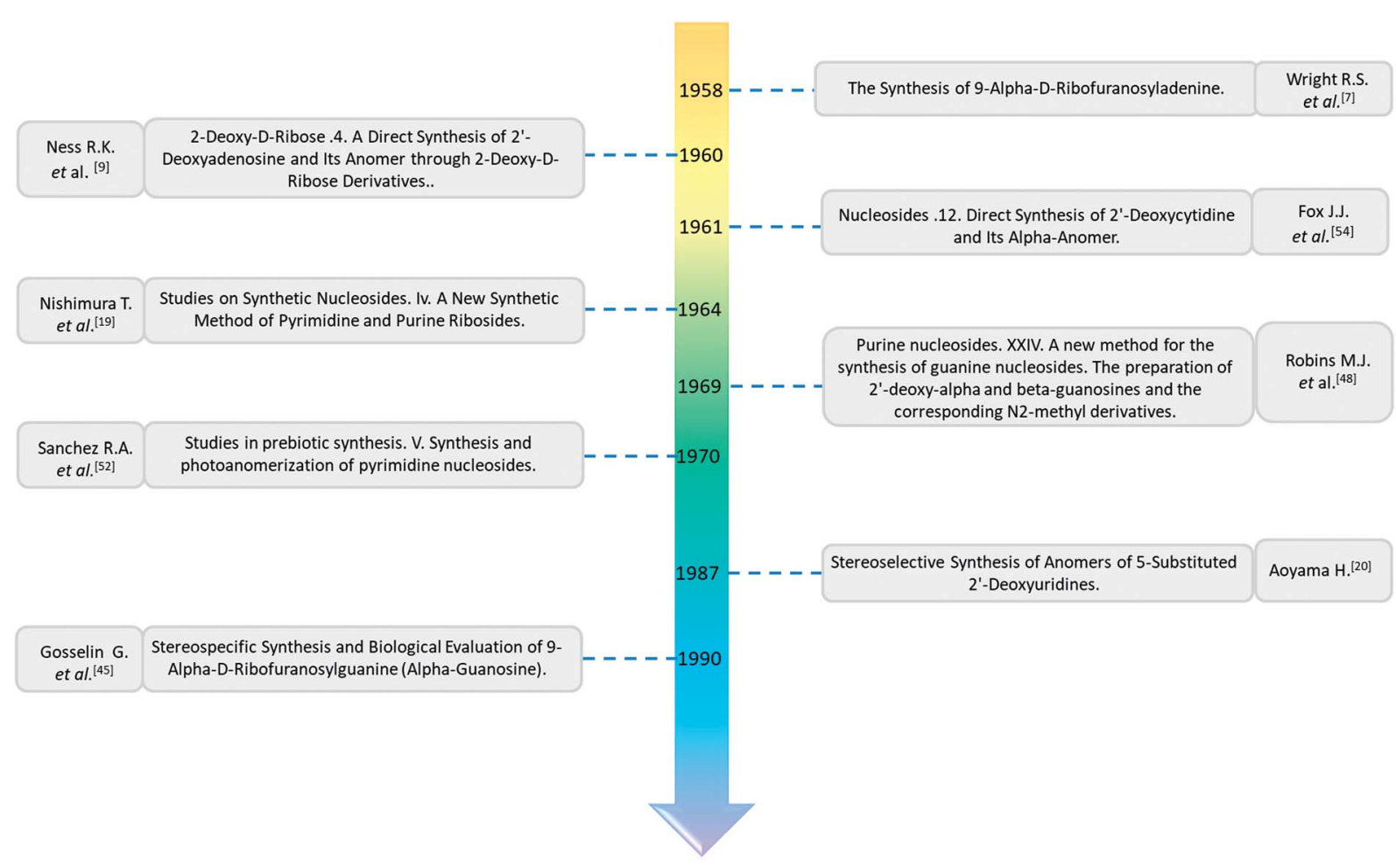

Fig. 13 First synthesis of various $\alpha$-nucleosides. 


\subsection{Parallel double helix}

In general, the naturally occurring duplexes DNA or RNA follow the Watson-Crick model, and the two strands of the double helix are in an antiparallel relationship with each other, and this rule also applies to $\alpha$-duplexes. In fact, in 1987, Morvan $^{72}$ et al. have pointed out that $\alpha$-[d(CATGCG)] can form an antiparallel double-stranded structure with complementary $\alpha$-oligodeoxynucleotide. However, differences are observed when the hybridization occurs between the $\alpha$-oligonucleotide and the $\beta$ oligonucleotide. Also in $1987, \mathrm{Sun}^{73}$ et al. synthesized an $\alpha$-oligodeoxyribonucleotide with the sequence $5^{\prime}$ d(TCTAAACTC) $3^{\prime}$, and used a pentamethylene linker to link a 9-amino acridine derivative with its $5^{\prime}$-phosphate. They also synthesized two $\beta$ oligodeoxyribonucleotides, containing complementary sequences in the $5^{\prime} \rightarrow 3^{\prime}$ or $3^{\prime} \rightarrow 5^{\prime}$ orientation, respectively. As illustrated in Fig. 14, the results indicate that an $\alpha$-oligodeoxyribonucleotide can form a double helix structure with an $\beta$ oligodeoxyribonucleotide, and interestingly, they adopted a parallel $5^{\prime} \rightarrow 3^{\prime}$ orientation. And in the same year, Morvan ${ }^{74}$ et al. also confirmed that the $\alpha$-oligodeoxynucleotides, $\alpha$-d [CATGCG] can form parallel double-stranded structure with complementary $\beta$-oligodeoxynucleotides. Similarly, in 1988, Praseuth $^{75}$ et al. also demonstrated that $\alpha$-octathymidylate can form a parallel double-stranded structure with complementary $\beta$-oligodeoxynucleotide. In addition, they found that $\alpha$-octathymidylate can be incorporated into complementary DNA duplexes to form a local triple helix structure which parallel to the complementary adenine strand. And in 1991, because homopyrimidine oligonucleotides can recognize the base pair sequence of double helix DNA and bind to the homopurine, $\mathrm{Sun}^{76}$ et al. synthesized 11-mer $\alpha$ - and $\beta$-oligodeoxynucleotides with the sequence $5^{\prime}-\mathrm{d}$ (TCTCCTCCTTT)- $3^{\prime}$ and bound them to the corresponding DNA duplex to form a local triple helix. Here, the $\alpha$-oligodeoxynucleotide has an anti-parallel structure with the homopurine strand, and the $\beta$-oligodeoxynucleotide adopted a parallel orientation. They believe that the formation of Hoogsteen hydrogen bonds in the triple helix is responsible for the anti-parallel structure of the $\alpha$-oligonucleotides to the homologous strand. Furthermore, In 1992, Debart ${ }^{77}$ et al. synthesized an $\alpha$-oligoribonucleotide, $\alpha$-[r(UCUUAACCCACA)], consisting entirely of $\alpha$-ribonucleotides, this oligoribonucleotide with highly nuclease-resistant can form a $2 \alpha$-RNA:1 $\beta$-DNA triple helix structure with complementary $\beta$-DNA sequence, wherein both $\alpha$-RNAs are parallel to $\beta$-DNA. In addition, this $\alpha$ RNA also exhibits inhibition of the de novo HIV-1 infection in cells without sequence specific.
Interestingly, in $1995, \mathrm{Koga}^{78}$ et al. used synthetic $5^{\prime}$-phosphoramidite derivatives of $\alpha$-deoxynucleoside and commercial 3 -phosphoramidite derivatives of $\beta$-deoxynucleoside as raw materials, and adopted standard solid-phase synthesis methods to construct $\alpha$-containing oligodeoxynucleotides with alternating $\alpha$-deoxynucleosides and $\beta$-deoxynucleosides, which have strong resistance to phosphatase. In recognition of the complementary native $\beta$-oligodeoxynucleotide, the sequence specificity of hybrid strand was similar to that of the native oligonucleotide, even though the thermal stability of the duplex which containing the hybrid strand is lower than the native DNA duplex. Furthermore, compared to the both strands are hybrid strands, CD spectrum confirmed that the helicity of a duplex containing only one hybrid strand is more similar to the native DNA. It is worth mentioning that this hybrid strand can also form a duplex with a complementary $\beta$-oligoribonucleotide, but the thermal stability is significantly lower than that of the hybrid strand: $\beta$-oligodeoxynucleotide complex.

It should be clear that this parallel double helix structure was limited to regions containing $\alpha$-nucleotides and unusual phosphodiester linkages; in fact, the $\alpha$-containing duplexes could form an approximately antiparallel double-stranded structure except for the position of the $\alpha$-nucleoside, ${ }^{79}$ which shown in Fig. 15.

Furthermore, in 1987, Gagnor ${ }^{80}$ et al. hybridized $\alpha$ and $\beta$ anomer d(G2T12G2) oligodeoxyribonucleotides to rA12 and compared their properties. They observed melting temperatures of $27.4{ }^{\circ} \mathrm{C}$ for $\beta$-oligodeoxyribonucleotide/RNA hybrid and $52.8{ }^{\circ} \mathrm{C}$ for $\alpha$-oligodeoxyribonucleotide/RNA, indicating that the double strand containing the $\alpha$-nucleoside has a higher melting temperature. Interestingly, in 1989, Paoletti ${ }^{81}$ et al. studied the melting temperatures of three sequences, $\alpha-d(C C T T C C): \beta-$ $\mathrm{d}($ GGAAGG), $\beta$-d(CCTTCC): $\beta$-d(GGAAGG) and $\alpha-\mathrm{d}($ GGAAGG): $\beta$ $\mathrm{d}(\mathrm{CCTTCC})$, and found values of $28.1{ }^{\circ} \mathrm{C}, 20.2{ }^{\circ} \mathrm{C}$, and $13.8^{\circ} \mathrm{C}$, respectively. These results suggest that the properties of the $\alpha$ sequence greatly impact the stability of the double strand.

\subsection{Biological properties}

Interestingly, $\alpha$-nucleosides and their derivatives also have a variety of specific biological properties, such as the antitumor, anti-bacterial, anti-malarial effects, inhibition of RNase $\mathrm{H}$ and potential for antisense therapy.

In 1972, Christensen ${ }^{13}$ et al. pointed out that although the inhibitory activity is lower than the corresponding $\beta$-nucleoside derivative, 2-chloro- $\alpha$ - $2^{\prime}$-deoxyadenosine and 2-methoxy- $\alpha-2$ deoxyadenosine significantly inhibits leukemia L1210 cells, in $[\alpha]$

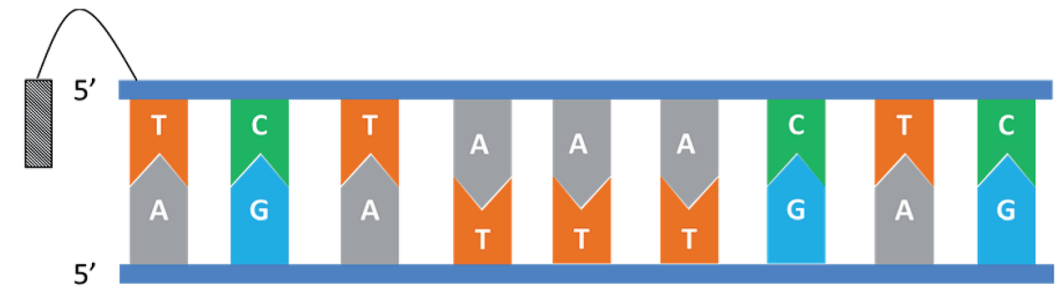

Fig. 14 An $\alpha$-oligodeoxyribonucleotide forms a parallel double strand with the $\beta$-oligodeoxyribonucleotide. 


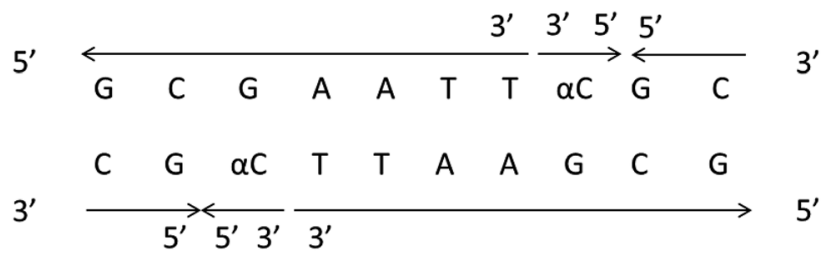

Fig. $15 \alpha$-Containing duplexes can form an overall anti-parallel $\beta$ DNA structure, the interference limited to the regions containing $\alpha$ nucleotides and unusual phosphodiester linkages.

addition, 2-hydrazino- $\alpha-2^{\prime}$-deoxyadenosine and 2-chloro- $\alpha-2^{\prime}$ deoxyadenosine also showed growth inhibition of Escherichia coli and Streptococcus faecium, respectively. And In 1975, Bobek $^{82}$ et al. discovered that $\alpha$ anomers of $4^{\prime}$-thio-5fluorouridine has similar properties. Moreover, in 1979, Acton $^{50}$ et al. proposed that $\alpha-2^{\prime}$-deoxythioguanosine has antitumor (lymphosarcoma) activity. Importantly, this compound is less toxic to the bone marrow than the corresponding $\beta$ anomer, and thus higher concentrations can be used to achieve higher efficacy. Furthermore, in 1993, when studying the inhibitory effect of nucleoside derivatives on tumors, Bretner ${ }^{34}$ et al. found that although the $\alpha$-anomer was less active than the corresponding $\beta$-anomer, it showed higher selectivity for tumor cells. Additionally, in 1998, Townsend ${ }^{83}$ et al. synthesized a series of 2substituted derivatives of 5,6-dichloro-1-( $\alpha$-L/D-lyxofuranosyl) benzimidazole and 1-(5-deoxy- $\alpha$-L/D-lyxofuranosyl)-5,6-dichlorobenzimidazole and studied their inhibition of human cytomegalovirus (HCMV) and herpes simplex virus type 1 (HSV-1). The results indicated that all of these derivatives had no or only weak inhibition on HSV-1, while for HCMV, most derivatives such as 2-isopropylamino or benzylthio derivatives had only weak inhibition, however, 2-halogen derivatives have significant inhibitory effects on the Towne strain of HCMV, especially 5 -deoxy $\alpha$-L-analogues exhibit the strongest inhibitory effect. And in 2007, Van Daele ${ }^{41}$ et al. synthesized a series of $5^{\prime}$ thiourea-substituted $\alpha$-thymidine derivatives and found that the derivative with a (3-trifluoromethyl-4-chlorophenyl)thiourea moiety significantly inhibited thymidine monophosphate kinase, and thus strongly inhibited growing Mycobacterium bovis $\left(\mathrm{MIC}_{99}=20 \mu \mathrm{g} \mathrm{mL}^{-1}\right.$ ) and Mycobacterium tuberculosis $\left(\mathrm{MIC}_{50}=6.25 \mu \mathrm{g} \mathrm{mL}^{-1}\right)$ strains. Based on these results, Cuii ${ }^{42}$ et al. synthesized the $\alpha$-anomer of $3^{\prime}$-azido- $2^{\prime}, 3^{\prime}$-dideoxythymidine in 2010, which significantly inhibited the growth of Plasmodium species with $\mathrm{EC}_{50}$ values in the micromolar range. Later, in 2012, ${ }^{44}$ they synthesized a series of thymidine analogues that showed anti-malarial effects by inhibiting Plasmodium falciparum thymidylate kinase (PfTMPK). Among them, $N$-(5'-deoxy- $\alpha$-thymidin-5'-yl)- $N^{\prime}$-[4-(2-chlorobenzyloxy)phenyl] urea was reported to be the most effective inhibitor of $P$. falciparum growth, with an $\mathrm{EC}_{50}$ value of $28 \mathrm{nM}$ and $\mathrm{CC}_{50}$ of $29 \mu \mathrm{M}$. Therefore, $\alpha$-nucleosides may have development potential as anti-tumor, anti-bacterial, and anti-parasitic drugs.

Furthermore, $\alpha$-nucleosides strongly inhibit RNase H. In 1988, Bloch $^{84}$ et al. showed that RNase $\mathrm{H}$, which uses a DNA:RNA duplex as a natural substrate, was inhibited when it bound to a non-physiological $\alpha$-DNA: $\beta$-RNA hybrid. And In 1996, Shinozuka $^{85}$ et al. conducted a more in-depth study of the inhibitory effects of $\alpha$-dC12, $\beta$-dC12, $\alpha$-S-dC12, $\beta$-S-dC12, $\alpha$-T15, $\beta$-T15, $\alpha$-ST15, and $\beta$-S-T15 on RNase H("S-" stands for a phosphorothioate linkage). The results showed that the $\alpha$-anomeric-2deoxycytidylate phosphorothioate was the most potent inhibitor $(>40 \%)$. In fact, RNase $\mathrm{H}$ catalyzes the degradation of the RNA portion of DNA-RNA hybrids, which is an inevitable step in the reverse transcription of retroviruses and thus essential for the replication of retroviruses such as HIV. Therefore, $\alpha$-nucleosides also show potential as antiretroviral drugs.

To date, there are no reports of $\alpha$-anomeric lesions in mammals. However, tumor cells can grow and proliferate in hypoxic environments. Radiation treatments create conditions that promote $\alpha$-anomeric damage. For example, when DNA is subjected to $\gamma$-irradiation under anoxic conditions, the $\alpha$ anomer of $2^{\prime}$-deoxyadenosine $(\alpha-\mathrm{dA})$ is the major product of DNA damage, ${ }^{86}$ as illustrated in Fig. 16.

In fact, when $\alpha$-dA is present in a DNA duplex, it is mutagenic and directs the incorporation of $\mathrm{dC}, \mathrm{dA}$, or $\mathrm{T}$ during replication in vitro, and in vitro. Under in vivo conditions, it will result in the deletions of single nucleotides. ${ }^{87}$ Even so, $\alpha$-dA is "gentler" than other $\alpha$-anomeric lesions. In 2015, Amato ${ }^{88}$ et al. found that without SOS induction, $\alpha-\mathrm{T}, \alpha$-dG and $\alpha$-dC nearly completely blocked DNA replication with only 1-3\% bypass efficiency, while $\alpha$-dA only caused medium blockade of replication with a bypass efficiency of $24 \%$. Interestingly, unlike many other damaged DNA nucleobases, the $\alpha \mathrm{dA}$ lesion was not repaired by DNA glycosylases and AP lyases, Instead, E. coli endonuclease IV (Nfo) directly incised the phosphodiester bond $5^{\prime}$ to the lesion in DNA. And in 2004, Ishchenko ${ }^{89}$ et al. pointed out that not only Nfo, but also Saccharomyces cerevisiae Apn1 protein, a homologue of Nfo and human major AP endonuclease 1, are involved in the alternative nucleotide incision repair pathway. However, in 2016, Timofeyeva ${ }^{90}$ et al. showed that the efficiency of $\alpha$-dA lesion conversion by APE1 is very low. They suggested that this is because although the $\alpha$-dA structure promotes enzyme recognition, the formation of the catalytically active complex and hydrolysis of the $5^{\prime}$-phosphodiester bond are greatly hindered. However, the identification and efficacy of enzymes is affected by the flanking sequences of $\alpha$-dA, as suggested by

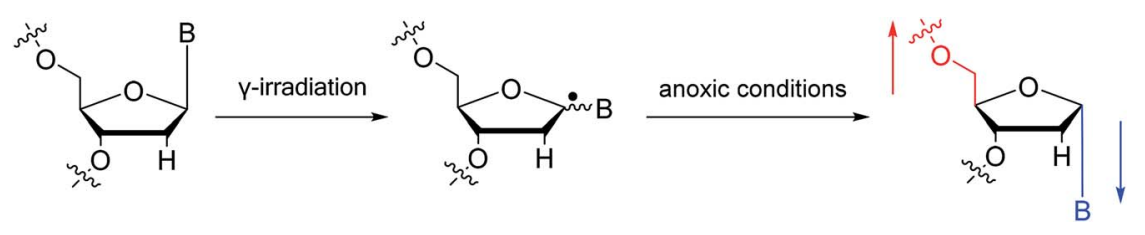

Fig. 16 Formation of $\alpha-2$ '-deoxynucleosides when DNA is subjected to $\gamma$-irradiation under anoxic conditions. And 'B' indicates nucleobase. 
Johnson $^{87}$ et al. in 2012. They found that the $5^{\prime} \mathrm{C} \alpha \mathrm{dAG} 3^{\prime}$ sequence was unique because its KM value was approximately four-fold that of other substrates $\left(5^{\prime} \mathrm{G} \alpha \mathrm{dAC} 3^{\prime}, 5^{\prime} \mathrm{G} \alpha \mathrm{dAG} 3^{\prime}\right.$, $\left.5^{\prime} \mathrm{C} \alpha \mathrm{dAC} 3^{\prime}\right)$, suggesting a lower affinity with Nfo for the $5^{\prime} \mathrm{C} \alpha \mathrm{dAG} 3^{\prime}$ duplex compared to that of the other substrates. Furthermore, in 2017, Williams ${ }^{91}$ et al. pointed out that human polymerase (Pol) $\eta$ can bypass all $\alpha$-dN damage and extend primers to generate full-length replication products.

However, although $\alpha$-anomeric lesions cause genetic damage, they show potential for use in antisense therapy. Antisense nucleotides refer to RNA or DNA molecules capable of precisely complementary to a specific mRNA and specifically blocks the expression of the target gene, resulting in low or no expression. As a gene regulatory factor, it plays an important role in inhibiting the expression of some harmful genes and overexpression of uncontrolled genes. As we mentioned above, $\alpha$-anomeric lesions can precisely pair with the target sequence and significantly block DNA replication. In fact, in 1995, Boiziau ${ }^{92}$ et al. have constructed 17-mer oligodeoxynucleotides containing 2,7 , or $12 \alpha$-nucleotides, respectively, and studied the inhibitory effects of these hybrids on the reverse transcription of Moloney Murine Leukemia Virus (MMLV). The results showed that these $\alpha$-containing oligodeoxynucleotides with only $5^{\prime}$ end can inhibit reverse transcription, and the hybrid strand with a longer $\beta$ region has a stronger inhibitory effect. This suggests that oligonucleotides containing $\alpha$ nucleotides have the potential to be retroviral antisense therapeutics. It should be noted that purely $\alpha$-oligonucleotide (the entire strand is composed of $\alpha$-nucleotides) is not suitable for the field of antisense therapy. Because in 1996, Aramini ${ }^{93}$ et al. pointed out that although purely $\alpha$-oligonucleotide can form stable structures with their targets and are not degraded by nucleases, these complexes are RNase $\mathrm{H}$ resistant. Unlike purely $\alpha$-anomeric, the oligodeoxynucleotides incorporating a single $\alpha$ nucleoside have RNase $\mathrm{H}$ activity. Thus, these oligodeoxynucleotides show ideal properties of antisense nucleotides as proposed by Germann ${ }^{79}$ et al. in 1997, including (1) highly nuclease resistant; (2) capable of forming a stable complex with its messenger RNA target; and (3) sensitive to RNase $H$. Thus, $\alpha$-nucleosides have potential value for use in antisense therapy. And in 1997, Aramini $^{94}$ et al. constructed four self-complementary DNA decamer duplexes [GCGAATTCGC] and inserted $\alpha \mathrm{A}, \alpha \mathrm{T}, \alpha \mathrm{G}$ and $\alpha \mathrm{C}$ into different locations in the strand in the opposite direction through $3^{\prime} \rightarrow 3^{\prime}$ and $5^{\prime} \rightarrow 5^{\prime}$ phosphodiester linkages. They demonstrated that all of these DNA sequences formed stable duplexes, and the structure of the four double-strands was similar to the control $\beta$ $\beta$ double strand. The double-strands containing $\alpha \mathrm{A}, \alpha \mathrm{T}$, and $\alpha \mathrm{G}$ showed similar thermal stability values as the control, and $\alpha \mathrm{C}$ insertion had the most deleterious effects on thermodynamic and structural properties. Therefore, the type, content and location of $\alpha$-nucleosides are important for the rational design of antisense molecules. It is worth mentioning that in 1998, Morvan $^{38}$ et al. synthesized 5-propynyl- $\alpha$-oligodeoxynucleotides mainly containing deoxyuridine and deoxycytidine, and they confirmed that these oligodeoxynucleotides can form more stable duplexes with the corresponding DNA or RNA. Similarly, in 2002, $\mathrm{Naval}^{\mathbf{1 6}}$ et al. synthesized 2-amino- $\alpha$-2'-deoxyadenosine and incorporated it into the methoxyethylphosphoramidate $\alpha$-oligodeoxynucleotides, which made the $\alpha$-oligodeoxynucleotides to form more stable complexes with the target RNA. And in 2010, Morvan $^{95}$ et al. also concluded that modified, especially cationically modified $\alpha$ oligonucleotides can form more stable double-strands or threestranded structure with target RNA or DNA than modified $\beta$ oligonucleotides. And these backbone-modified $\alpha$-oligonucleotides are also considered to have potential for application in the field of antisense therapy due to their good selectivity to targets, high nuclease resistance and other properties.

\subsection{Other properties}

In addition to the various properties mentioned above, some other properties such as higher affinity for protons, unique fluorescent properties and reasons for selection of $\beta$-RNA need to be mentioned.

In 2005, Müller ${ }^{96}$ et al. found that some nucleoside derivatives such as imidazole nucleosides can form stable complexes with metal ions like silver ions. On this basis, they conducted a similar study on the $\alpha$-anomers of these nucleoside derivatives in $2007 .{ }^{97}$ The results showed that the $\alpha$-nucleoside derivatives had significantly higher affinity for protons than their $\beta$ anomers. Similarly, the metal-ion complexes of the $\alpha$-anomers were more stable than their $\beta$-anomers. Thus, $\alpha$-nucleosides have the potential to be developed into nucleoside-based nanostructures and devices. And in 2017, Seela ${ }^{98}$ et al. constructed a silver-mediated base pair by using $\alpha$-dC and $\beta$-dC. They found that compared to the $\beta-\beta$ duplex $\left(T_{\mathrm{m}}=34{ }^{\circ} \mathrm{C}\right)$, a 12 mer duplex with $\alpha$-dC exhibited better thermal stability $\left(T_{\mathrm{m}}=43\right.$ ${ }^{\circ} \mathrm{C}$ ). They also found that $\alpha$-dC has an excellent ability to identify DNA single-nucleotide polymorphism mismatches.

And in 2018, Seela ${ }^{51}$ et al. prepared a series of 12-mer oligodeoxyribonucleotides incorporating $\alpha$-anomers of 8 -aza- $2^{\prime}$ deoxyguanosine $\left(\alpha \mathrm{G}_{\mathrm{d}}^{*}\right), \alpha \mathrm{G}_{\mathrm{d}}, \quad \beta$-anomers of 8 -aza-2'-deoxyguanosine $\left(\beta \mathrm{G}_{\mathrm{d}}^{*}\right)$ and $\beta \mathrm{G}_{\mathrm{d}}$. They found that oligodeoxyribonucleotides containing $\alpha \mathrm{G}_{\mathrm{d}}^{*}$ showed high fluorescence at $\mathrm{pH}$ (8.0). However, the fluorescence changed when a duplex DNA was formed with A, T, G, and C, and the duplex containing the $\alpha G_{d}^{*}-C_{d}$ base pair showed the strongest fluorescence decrease. They also found that decreased fluorescence corresponded to a higher $T_{\mathrm{m}}$ value, and the duplex containing $\alpha \mathrm{G}_{\mathrm{d}}^{*}-\mathrm{C}_{\mathrm{d}}$ showed better thermal stability than $\alpha \mathrm{G}_{\mathrm{d}}-\mathrm{C}_{\mathrm{d}}$. Additionally, the results showed that the $\alpha$-anomers were more efficient than $\beta$-nucleosides for mismatch distinction.

Interestingly, in 1997, Sawai ${ }^{99}$ et al. discussed the selective advantages of $\beta$-RNA compared to $\alpha$-RNA. They suggested that during the process of chemical evolution, both $\alpha$ - and $\beta$-glycosidic nucleosides could be formed. However, they found that under the same conditions, the yield and chain length of the $\beta$ oligomer were much higher than those of the corresponding $\alpha$ oligomer. Therefore, they hypothesized that a possible explanation for the selectivity advantage of $\beta$-RNA is that the formation of $\beta$-oligomers is easier than that of $\alpha$-oligomers. Additionally, depending on changes in temperature, forming a ternary structure of single-stranded oligoribonucleotides more easily and better conformational flexibility may be important factors in the selection of $\beta$-RNA over $\alpha$-RNA. 


\section{Conclusion}

In summary, since Kaplan proposed the concept of the $\alpha$-configuration in 1955, only five $\alpha$-nucleosides or derivatives present in nature have been reported. A series of $\alpha$-nucleosides and derivatives were artificially synthesized by methods such as the mercuri procedure, fusion reactions, self-anomerization or Vorbrüggen glycosylation. Additionally, some unique properties of $\alpha$-nucleosides, including the stability or inhibition of enzymes, parallel double-stranded structure of $\alpha-\beta$ duplex, fluorescent properties, and inhibition of tumors, bacteria and Plasmodium, suggest their application prospects. These molecules may be useful in gene regulation, antiretroviral drugs, antitumor drugs, and genetic mismatch identification, among others. It is conceivable that more applications of $\alpha$-nucleosides have not yet been discovered. For example, because of the special spatial conformation of $\alpha$-nucleosides, whether they achieve base pairing in a new manner that differs from the traditional Watson-Crick principle requires further evaluation. Additionally, studies are needed to determine whether $\alpha$-nucleosides can form structures such as G-quartets or Cpentamers like their $\beta$-anomers. Although the antitumor and antiretroviral effects of $\alpha$-nucleosides have been confirmed, they have not been used in clinical treatment. Therefore, as a drug or drug carrier, $\alpha$-nucleosides may have broad applications in the future. Furthermore, the use of $\beta$-guanosine in the field of supramolecular hydrogels has made considerable progress, ${ }^{\mathbf{1 0 0}}$ but no studies have reported the properties of hydrogels constructed from $\alpha$-guanosine. Considering the better stability of $\alpha$-nucleosides against external conditions such as enzymes and temperature, if $\alpha$ nucleosides can be used to form supramolecular hydrogels, they can be used in more extreme environments. In conclusion, through multidisciplinary integration, including the fields of biochemistry, materials science, and medicine, additional properties of $\alpha$-nucleosides will be identified to broaden their application prospects. Finally, if we inadvertently miss some important research by any scholars, we sincerely apologize for this, and we hope that readers will point these omissions out, which will help us further summarize the $\alpha$-nucleosides in the future.

\section{Conflicts of interest}

There are no conflicts to declare.

\section{Funding}

National Natural Science Foundation of China (81621062).

\section{Acknowledgements}

The authors gratefully acknowledge support from the National Natural Science Foundation of China (81621062, 81500860, 81700988) and Outstanding Young Scholar Fund (20826041A4403) from the Sichuan University for financial support.

\section{References}

1 U. Sequin, Experientia, 1973, 29, 1059-1062.

2 N. O. Kaplan, M. M. Ciotti, F. E. Stolzenbach and N. R. Bachur, J. Am. Chem. Soc., 1955, 77, 815-816.

3 S. Suzuki, K. Suzuki, T. Imai, N. Suzuki and S. Okuda, J. Biol. Chem., 1965, 240, P554-P556.

4 R. Bonnett, Chem. Rev., 1963, 63, P573-P605.

5 H. G. Gassen and H. Witzel, Biochim. Biophys. Acta, 1965, 95, 244-250.

6 F. Dinglinger and P. Renz, Hoppe-Seyler's Z. Physiol. Chem., 1971, 352, 1157-1161.

7 R. S. Wright, G. M. Tener and H. G. Khorana, J. Am. Chem. Soc., 1958, 80, 2004-2006.

8 G. Schramm, G. Lunzmann and F. Bechmann, Biochim. Biophys. Acta, 1967, 145, 221-227.

9 R. K. Ness and H. G. Fletcher, J. Am. Chem. Soc., 1960, 82, 3434-3437.

10 J. J. K. Novak and F. Sorm, Collect. Czech. Chem. Commun., 1962, 27, 902-905.

11 M. J. Robins and R. K. Robins, J. Am. Chem. Soc., 1965, 87, 4934-4940.

12 M. J. Robins, T. A. Khwaja and R. K. Robins, J. Org. Chem., 1970, 35, 636-639.

13 L. F. Christensen, A. D. Broom, M. J. Robins and A. Bloch, J. Med. Chem., 1972, 15, 735-739.

14 J. B. Hobbs and F. Eckstein, J. Org. Chem., 1977, 42, 714719.

15 M. Imazawa and F. Eckstein, J. Org. Chem., 1979, 44, 20392041.

16 M. Naval, T. Michel, J. J. Vasseur and F. Debart, Bioorg. Med. Chem. Lett., 2002, 12, 1435-1438.

17 S. Ye, M. M. Rezende, W. P. Deng, B. Herbert, J. W. Daly, R. A. Johnson and K. L. Kirk, J. Med. Chem., 2004, 47, 1207-1213.

18 G. G. Sivets, E. N. Kalinichenko and I. A. Mikhailopulo, Helv. Chim. Acta, 2007, 90, 1818-1836.

19 T. Nishimura, B. Shimizu and I. Iwai, Chem. Pharm. Bull., 1964, 12, 1471-1478.

20 H. Aoyama, Bull. Chem. Soc. Jpn., 1987, 60, 2073-2077.

21 B. Shimizu, A. Saito, T. Nishimura and M. Miyaki, Chem. Pharm. Bull., 1967, 15, 2011-2014.

22 H. J. Minnemeyer, P. B. Clarke and H. Tieckelmann, J. Med. Chem., 1964, 7, 567-569.

23 K. J. Ryan, E. M. Acton and L. Goodman, J. Org. Chem., 1966, 31, 1181-1184.

24 M. P. Kotick, C. Szantay and T. J. Bardos, J. Org. Chem., 1969, 34, 3806-3813.

25 G. L. Bubbar and V. S. Gupta, Can. J. Biochem., 1970, 48, 3147-3153.

26 T. Kulikowski and D. Shugar, J. Med. Chem., 1974, 17, 269273.

27 R. A. Sharma and M. Bobek, J. Org. Chem., 1975, 40, 23772379.

28 V. W. Armstrong, J. K. Dattagupta, F. Eckstein and W. Saenger, Nucleic Acids Res., 1976, 3, 1791-1810. 
29 A. J. Brink, O. G. de Villiers and A. Jordaan, J. Chem. Soc., Perkin Trans. 1, 1977, 1608-1612.

30 P. J. Barr, A. S. Jones, P. Serafinowski and R. Walker, J. Chem. Soc., Perkin Trans. 1, 1978, 1263-1267.

31 H. Griengl, M. Bodenteich, W. Hayden, E. Wanek, W. Streicher, P. Stutz, H. Bachmayer, I. Ghazzouli and B. Rosenwirth, J. Med. Chem., 1985, 28, 1679-1684.

32 M. Bobek, I. Kavai and E. De Clercq, J. Med. Chem., 1987, 30, 1494-1497.

33 P. Wigerinck, C. Pannecouque, R. Snoeck, P. Claes, E. De Clercq and P. Herdewijn, J. Med. Chem., 1991, 34, 23832389.

34 M. Bretner, T. Kulikowski, J. M. Dzik, M. Balinska, W. Rode and D. Shugar, J. Med. Chem., 1993, 36, 3611-3617.

35 A. A. Elbarbary, A. I. Khodair, E. B. Pedersen and C. Nielsen, Monatsh. Chem., 1994, 125, 593-598.

36 U. Wellmar, A. B. Hornfeldt, S. Gronowitz and N. G. Johansson, Chem. Heterocycl. Compd., 1996, 32, 1312-1318.

37 Y. Diaz, A. ElLaghdach and S. Castillon, Tetrahedron, 1997, 53, 10921-10938.

38 F. Morvan, J. Zeidler and B. Rayner, Tetrahedron, 1998, 54, 71-82.

39 E. Colacino, G. Sindona, G. Gosselin and C. Mathe, Nucleosides, Nucleotides Nucleic Acids, 2003, 22, 2013-2026.

40 M. Ogino, Y. Yoshimura, A. Nakazawa, I. Saito and K. Fujimoto, Org. Lett., 2005, 7, 2853-2856.

41 I. Van Daele, H. Munier-Lehmann, M. Froeyen, J. Balzarini and S. Van Calenbergh, J. Med. Chem., 2007, 50, 5281-5292.

42 H. Q. Cui, L. M. Ruiz-Perez, D. Gonzalez-Pacanowska and I. H. Gilbert, Bioorg. Med. Chem., 2010, 18, 7302-7309.

43 X. Liu, X. L. Xia, C. H. Sun, C. Lin, Y. Q. Zhou, M. Hussain, F. Tang, L. Liu, X. Li and J. C. Zhang, Nucleosides, Nucleotides Nucleic Acids, 2016, 35, 479-494.

44 H. Q. Cui, J. Carrero-Lerida, A. P. G. Silva, J. L. Whittingham, J. A. Brannigan, L. M. Ruiz-Perez, K. D. Read, K. S. Wilson, D. Gonzalez-Pacanowska and I. H. Gilbert, J. Med. Chem., 2012, 55, 10948-10957.

45 G. Gosselin, M. C. Bergogne and J. L. Imbach, Nucleosides Nucleotides, 1990, 9, 81-87.

46 K. I. Imai, A. Nohara and M. Honjo, Chem. Pharm. Bull., 1966, 14, 1377-1381.

47 H. Iwamura, M. Miyakado and T. Hashizum, Carbohydr. Res., 1973, 27, 149-156.

48 M. J. Robins and R. K. Robins, J. Phys. Chem., 1969, 34, 2160-2163.

49 F. Morvan, in Protocols for Oligonucleotides and Analogs, ed. S. Agrawal, Humana Press, Totowa, NJ, 1993, ch. 13, vol. 20, pp. 261-283.

50 E. M. Acton, R. N. Goerner, H. S. Uh, K. J. Ryan, D. W. Henry, C. E. Cass and G. A. Lepage, J. Med. Chem., 1979, 22, 518525.

51 J. Liu, S. A. Ingale and F. Seela, Bioconjugate Chem., 2018, 29, 2265-2277.

52 R. A. Sanchez and L. E. Orgel, J. Mol. Biol., 1970, 47, 531543.
53 H. Sawai, A. Nakamura, H. Hayashi and K. Shinozuka, Nucleosides Nucleotides, 1994, 13, 1647-1654.

54 J. J. Fox, M. Hoffer, I. Wempen and N. C. Yung, J. Am. Chem. Soc., 1961, 83, 4066-4070.

55 R. Duschinsky, T. Gabriel, M. Hoffer, J. Berger, E. Titsworth, E. Grunberg, J. H. Burchenal and J. J. Fox, J. Med. Chem., 1966, 9, 566-572.

56 E. Walton, S. R. Jenkins, R. F. Nutt and F. W. Holly, J. Med. Chem., 1969, 12, 306-309.

57 V. C. Solan, G. L. Szekeres, E. K. Ryu, H. Kung, Y. K. Ho and T. J. Bardos, Nucleosides Nucleotides, 1983, 2, 419-434.

58 D. Peters, A. B. Hornfeldt, S. Gronowitz and N. G. Johansson, Nucleosides Nucleotides, 1992, 11, 11511173.

59 M. Imazawa and F. Eckstein, J. Org. Chem., 1978, 43, 30443048.

60 T. Yamaguchi and M. Saneyoshi, Chem. Pharm. Bull., 1984, 32, 1441-1450.

61 Y. Sato, G. Tateno, K. Seio and M. Sekine, Tetrahedron Lett., 2002, 43, 3251-3254.

62 F. Seela, S. Menkhoff and S. Behrendt, J. Chem. Soc., Perkin Trans. 2, 1986, 525-530.

63 D. I. Ward, S. M. Jeffs, P. L. Coe and R. T. Walker, Tetrahedron Lett., 1993, 34, 6779-6782.

64 S. Janardhanam and K. P. Nambiar, Tetrahedron Lett., 1994, 35, 3657-3660.

65 Z. W. Wang and C. J. Rizzo, Tetrahedron Lett., 1997, 38, 8177-8180.

66 J. Garcia, A. Diaz-Rodriguez, S. Fernandez, Y. S. Sanghvi, M. Ferrero and V. Gotor, J. Org. Chem., 2006, 71, 9765-9771.

67 A. Hatano, A. Harano, Y. Takigawa, Y. Naramoto, K. Toda, Y. Nakagomi and H. Yamada, Bioorg. Med. Chem., 2008, 16, 3866-3870.

68 U. Sequin, Helv. Chim. Acta, 1974, 57, 68-81.

69 F. Morvan, B. Rayner, J. L. Imbach, S. Thenet, J. R. Bertrand, J. Paoletti, C. Malvy and C. Paoletti, Nucleic Acids Res., 1987, 15, 3421-3437.

70 N. T. Thuong, U. Asseline, V. Roig, M. Takasugi and C. Helene, Proc. Natl. Acad. Sci. U. S. A., 1987, 84, 5129-5133.

71 T. A. Bacon, F. Morvan, B. Rayner, J. L. Imbach and E. Wickstrom, J. Biochem. Biophys. Methods, 1988, 16, 311318.

72 F. Morvan, B. Rayner, J. L. Imbach, D. K. Chang and J. W. Lown, Nucleic Acids Res., 1987, 15, 4241-4255.

73 J. S. Sun, U. Asseline, D. Rouzaud, T. Montenay-Garestier, N. T. Thuong and C. Helene, Nucleic Acids Res., 1987, 15, 6149-6158.

74 F. Morvan, B. Rayner, J. L. Imbach, M. Lee, J. A. Hartley, D. K. Chang and J. W. Lown, Nucleic Acids Res., 1987, 15, 7027-7044.

75 D. Praseuth, L. Perrouault, T. L. Doan, M. Chassignol, N. Thuong and C. Helene, Proc. Natl. Acad. Sci. U. S. A., 1988, 85, 1349-1353.

76 J. S. Sun, C. Giovannangeli, J. C. Francois, R. Kurfurst, T. Montenay-Garestier, U. Asseline, T. Saisonbehmoaras, N. T. Thuong and C. Helene, Proc. Natl. Acad. Sci. U. S. A., 1991, 88, 6023-6027. 
77 F. Debart, B. Rayner, G. Degols and J. L. Imbach, Nucleic Acids Res., 1992, 20, 1193-1200.

78 M. Koga, A. Wilk, M. F. Moore, C. L. Scremin, L. Zhou and S. L. Beaucage, J. Org. Chem., 1995, 60, 1520-1530.

79 M. W. Germann, J. M. Aramini, B. W. Kalisch, R. T. Pon and J. H. Van de Sande, Nucleosides Nucleotides, 1997, 16, 14811485.

80 C. Gagnor, J. R. Bertrand, S. Thenet, M. Lemaitre, F. Morvan, B. Rayner, C. Malvy, B. Lebleu, J. L. Imbach and C. Paoletti, Nucleic Acids Res., 1987, 15, 10419-10436.

81 J. Paoletti, D. Bazile, F. Morvan, J. L. Imbach and C. Paoletti, Nucleic Acids Res., 1989, 17, 2693-2704.

82 M. Bobek, A. Bloch, R. Parthasarathy and R. L. Whistler, J. Med. Chem., 1975, 18, 784-787.

83 M. T. Migawa, J. L. Girardet, J. A. Walker 2nd, G. W. Koszalka, S. D. Chamberlain, J. C. Drach and L. B. Townsend, J. Med. Chem., 1998, 41, 1242-1251.

84 E. Bloch, M. Lavignon, J. R. Bertrand, F. Pognan, F. Morvan, C. Malvy, B. Rayner, J. L. Imbach and C. Paoletti, Gene, 1988, 72, 349-360.

85 K. Shinozuka, N. Yamada, A. Nakamura, H. Ozaki and H. Sawai, Bioorg. Med. Chem. Lett., 1996, 6, 1843-1848.

86 K. B. Lesiak and K. T. Wheeler, Radiat. Res., 1990, 121, 328337.

87 C. N. Johnson, A. M. Spring, S. Desai, R. P. Cunningham and M. W. Germann, J. Mol. Biol., 2012, 416, 425-437.
88 N. J. Amato, Q. Q. Zhai, D. C. Navarro, L. J. Niedernhofer and Y. S. Wang, Nucleic Acids Res., 2015, 43, 8314-8324.

89 A. A. Ishchenko, H. Ide, D. Ramotar, G. Nevinsky and M. Saparbaev, Biochemistry, 2004, 43, 15210-15216.

90 N. A. Timofeyeva and O. S. Fedorova, Mol. BioSyst., 2016, 12, 3435-3446.

91 N. L. Williams, N. J. Amato and Y. S. Wang, Chem. Res. Toxicol., 2017, 30, 1127-1133.

92 C. Boiziau, F. Debart, B. Rayner, J. L. Imbach and J. J. Toulme, FEBS Lett., 1995, 361, 41-45.

93 J. M. Aramini, B. W. Kalisch, R. T. Pon, J. H. vandeSande and M. W. Germann, Biochemistry, 1996, 35, 9355-9365.

94 J. M. Aramini, J. H. Van de Sande and M. W. Germann, Biochemistry, 1997, 36, 9715-9725.

95 F. Morvan, F. Debart and J. J. Vasseur, Chem. Biodiversity, 2010, 7, 494-535.

96 J. Müller, D. Bohme, P. Lax, M. Morell Cerda and M. Roitzsch, Chemistry, 2005, 11, 6246-6253.

97 J. Muller, D. Bohme, N. Dupre, M. Mehring and F. A. Polonius, J. Inorg. Biochem., 2007, 101, 470-476.

98 X. R. Guo and F. Seela, Chem.-Eur. J., 2017, 23, 1177611779.

99 H. Sawai, T. Itoh, K. Kokaji and K. Shinozuka, J. Mol. Evol., 1997, 45, 209-215.

100 T. Bhattacharyya, P. Saha and J. Dash, ACS Omega, 2018, 3, 2230-2241. 